\title{
Current-status and applications of polysaccharides in drug delivery systems
}

\author{
Parteek Prasher ${ }^{\mathrm{a}, * *}$, Mousmee Sharma ${ }^{\mathrm{b}}$, Meenu Mehta ${ }^{\mathrm{c}}$, Saurabh Satija ${ }^{\mathrm{c}, \mathrm{d}}$, Alaa A. Aljabali ${ }^{\mathrm{e}}$, \\ Murtaza M. Tambuwala ${ }^{f}$, Krishnan Anand ${ }^{g}$, Nitin Sharma ${ }^{h}$, Harish Dureja ${ }^{i}$, Niraj Kumar Jha ${ }^{j}$, \\ Gaurav Gupta $^{\mathrm{k}}$, Monica Gulati ${ }^{1}$, Sachin Kumar Singh ${ }^{1}$, Dinesh K. Chellappan ${ }^{\mathrm{m}}$, \\ Keshav R. Paudel $^{\text {n,o }}$, Philip M. Hansbro ${ }^{\text {n,o }}$, Kamal Dua ${ }^{\text {c,n, }}$

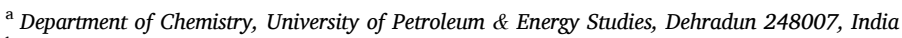 \\ ${ }^{\mathrm{b}}$ Department of Chemistry, Uttaranchal University, Dehradun 248007, India \\ ${ }^{\mathrm{c}}$ Discipline of Pharmacy, Graduate School of Health, University of Technology Sydney, NSW 2007, Australia \\ ${ }^{\mathrm{d}}$ School of Pharmaceutical Sciences, Lovely Professional University, Phagwara 144411, Punjab, India \\ e Yarmouk University, Faculty of Pharmacy, Department of Pharmaceutics and Pharmaceutical Technology, Irbid 566, Jordan \\ ${ }^{\mathrm{f}}$ School of Pharmacy and Pharmaceutical Science, Ulster University, Coleraine, County Londonderry, Northern Ireland BT52 1SA, United Kingdom \\ ${ }^{g}$ Department of Chemical Pathology, School of Pathology, Faculty of Health Sciences and National Health Laboratory Service, University of the Free State, Bloemfontein, \\ South Africa \\ ${ }^{\mathrm{h}}$ Department of Pharmacy, Merrut Institute of Engineering and Technology, UP 250005, India \\ i Department of Pharmaceutical Sciences, Maharshi Dayanand University, Rohtak 124001, India \\ ${ }^{\mathrm{j}}$ Department of Biotechnology, School of Engineering and Technology (SET), Sharda University, Greater Noida 201310, UP, India \\ ${ }^{\mathrm{k}}$ School of Pharmacy, Suresh Gyan Vihar University, Jaipur, Rajasthan, India \\ ${ }^{1}$ School of Pharmaceutical Sciences, Lovely Professional University, Jalandhar-Delhi G.T Road, Phagwara, Punjab, India \\ ${ }^{\mathrm{m}}$ Department of Life Sciences, School of Pharmacy, International Medical University, Bukit Jalil, 57000 Kuala Lumpur, Malaysia \\ ${ }^{\mathrm{n}}$ Centre for Inflammation, Centenary Institute, Sydney, NSW 2050, Australia \\ ${ }^{\circ}$ School of Life Sciences, Faculty of Science, University of Technology Sydney, Ultimo, NSW 2007, Australia
}

\section{A R T I C L E I N F O}

\section{Keywords:}

Polysaccharides

Drug delivery

Biocompatible

\begin{abstract}
A B S T R A C T
The polysaccharide-based advanced drug delivery system owing to their biocompatibility, ability to encapsulate the drug molecules in their interspaces, and ability to achieve a controlled release of the cargo drug molecules result in improved drug pharmacokinetics. The drug-loaded polysaccharides possess ability to evade the multidrug-resistant microbial efflux pumps by aggregation effect, whereas the drug loaded polysaccharidefabricated metal nanoparticles present an exceptional candidature for effectively transporting the drug molecules across the membrane barriers while enabling the theranostic applications at the same time. The biodegradability of polysaccharide based drug delivery systems ensure a sustained release of the encapsulated drug molecules, which minimizes the side effects caused by a burst release of the cargo therapeutics. These drug delivery systems proved highly beneficial for the NSAIDs that otherwise manifest ulcerogenic effect in the gastrointestinal tract. The large surface area of polysaccharides further provide a higher drug-loading capacity, which maintains the optimal concentration of the cargo drug at the target sites. The emerging applications of biodegradable polysaccharides in the designing of multicompartmental microspheres revolutionized tissue engineering, multi drug delivery, and cell culturing technologies. The present review deals with the current-status of polysaccharides as advanced drug delivery systems.
\end{abstract}

\section{Introduction}

Polysaccharides comprise of repeated mono- or disaccharide units connected via enzyme-susceptible glycosidic bonds, which support their applications as controlled release drug carriers. Their remarkable physicochemical and physiological properties such as biocompatibility, biodegradability and low immunogenicity [1-4] further validate the drug delivery applications. Usually, such natural polysaccharides are

\footnotetext{
* Corresponding author at: Discipline of Pharmacy, Graduate School of Health, University of Technology Sydney, NSW 2007, Australia.

$* *$ Corresponding author at: Department of Chemistry, University of Petroleum \& Energy Studies, Dehradun 248007, India.

E-mail addresses: parteekchemistry@gmail.com, pprasher@ddn.upes.ac.in (P. Prasher), Kamal.Dua@uts.edu.au (K. Dua).
} 
easily available from the plant, animals and microbes. Such polysaccharides possess various physicochemical properties such as being neutral or having positive or negative charge, being able to have linear or branched molecular structure, and their molecular weight can vary from a few hundred to several thousand Daltons [5-7]. Due to these properties, the polysaccharides have considerable impact on the biodistribution of carrier drug molecules in-vivo [8,9].

Numerous polysaccharides could even adhere to the layer of mucus, which covers epithelial surfaces throughout the body. Thus, the polysaccharide based carrier systems have extended in vivo residence time in gastrointestinal (GI) tract, thereby increasing drug bioavailability [10-14]. Cationic polysaccharides such as chitosan and its derivatives have the capacity to open the tight interconnections among epithelial cells, thereby increased hydrophilic drug permeability through mucus membranes [15-20].

The polysaccharides possess an inherent ability to recognize specific receptors, which over-express on the surface of morbid tissues. As such, hyaluronic acid specifically binds to the over-expressed CD44 receptor of several tumor cells [21]. In addition, pullulan reportedly possesses a high specificity towards asialoglycoprotein receptors that express at the surface hepatocytes [22]. The unique binding of these polysaccharides with certain receptors permits a rational designing of novel carriers, which selectively deliver the cargo drugs by means of receptor-mediated endocytosis [23-26].

Besides, the natural polysaccharides offer advanced applications as multi-drug delivery systems.

In this review, we present a comprehensive survey of the advanced applications of Polysaccharides in drug delivery and other biomedical applications and the various factors that determine the efficacy of these applications.

\section{Physicochemical factors}

The alterations and chemical modifications of the functional head groups such as $-\mathrm{COOH},-\mathrm{NH}_{2}$, and $-\mathrm{OH}$ on the polysaccharide structures led to the generation of polysaccharide derivatives with distinct properties for specific applications. Reportedly, the sulfonation of Pullulan ameliorates its anticoagulant activity compared to the nonsulphated counterpart. Whereas the thiolation of chitosan significantly improves its mucoadhesive properties compared to the non-thiolated counterpart $[27,28]$ owing to the formation of tight covalent bonds with cysteine-rich mucus glycoprotein subdomains by the former $[29,30]$.

The interactions with functional head groups on polysaccharides enables the incorporation of therapeutic drugs into the main chain through covalent bonds or electrostatic interactions followed by subsequent release of the incorporated drug at target site under a suitable stimuli [31,32]. Similarly, the amphiphilic derivatives of polysaccharides prepared by tethering the hydrophobic moieties to the parent chain possess self-assembly properties in physiological settings and present applications for the delivery of hydrophobic drug molecules such as paclitaxel to the target cells [33-36].

Zeta potential also plays an important role in the drug delivery applications by polysaccharides by influencing the interactions of polysaccharide nanosystems with proteins and cells [37]. The factors that generate a net charge on the surface of polysaccharide nanocarrier contribute towards the production of a high zeta potential. The dissociation of ionogenic surface group or adsorbed molecules, and the presence of other ions in parent solvent or on the surface of the molecule offer a significant contribution towards the zeta potential of nonionogenic polysaccharides. However, when the aqueous medium has no other electrolytes, the hydroxide ions adsorb on the surface of polysaccharide resulting in an overall negative surface load $[38,39]$.

The $\mathrm{pH}$ value of the medium in addition to the ionic strength, particle size and particle density considerably influence the zeta potential [40-42]. Acidic $\mathrm{pH}$ promotes the adsorption of protons due to increasing concentration (the zeta potential increases) while a reverse effect takes place at basic $\mathrm{pH}$ due to the elevated concentration of hydroxide ions. At a certain $\mathrm{pH}$ level, the zeta potential may become zero, leading to instability in the colloids and accumulation of particles. Increasing electrolyte rates in the parent medium usually result in the shielding of electrical charges. This result in to the compression of the electrical double layer that contributes to less electrostatic repulsion and colloid coagulation [43-45].

The phosphorylated chitosan-based micelles have been studied for their effect on mucosal drug delivery during the change in zeta potential. On contacting the alkaline phosphatase (cell surface glycoproteins found in many organs such as the intestine, the lungs and the vagina), the phosphorylated micelles undergo a split off to make the zeta potential from negative to positive or neutral [46-48]. An initial negatively charged surface enables the micelles to resist the binding of polysaccharide to negative charged components of the mucus and diffuse through the layer of the mucus. Whereas, a subsequent positive charge enhances the contact of polysaccharide with mucus and cell membranes thereby preventing the back diffusion, cellular premising and internalization $[49,50]$.

Biodegradable polysaccharides or biopolymer-based nanomaterials disintegrate during their intended function in physiological settings [51]. These polymers degrade in situ to generate the natural by-products such as water, carbon dioxide, and small organic molecules [52]. The backbone of these polysaccharides include functional groups of ester, amide, and ether that undergo enzymatic degradation in physiological environment [53]. Their structure and composition dictates the mechanisms of their degradation [54-56].

The backbone of polymeric materials consists of chemical bonds including polyesters, polyamides, and polyanhydrides that offer numerous implementations. The polymeric materials composed of carbohydrates consists of large chains of monosaccharide units that by hydrolysis produce the monosaccharide portion or the oligosaccharide component. Their constructions vary from linear to highly branched polymers. Minor differences in polysaccharide molecules can lead to a substantial difference in the properties [57]. As such, even the minor stereochemical differences in starch and cellulose result dramatically different functions. Click chemistry and radical polymerization techniques bind several polymers to the cellulose backbone due to the presence of several functional head groups on the polymeric backbone. Especially, the green polysaccharides have been of recent interest because their biodegradability and the materials based on these polysaccharides are ideal for absorption and subsequent removal from the body and the systemic circulation. Interestingly, the 500 odd species of bacteria in the intestinal tract make this environment an exceptional microbial ecosystem. The gut microbiota conduct a simple series of biochemical processes involving starch breakdown, vitamin synthesis, and fermentation, while the polysaccharide oxidation happens in the intestines [58]. A great deal of research has been done focused on alkaline polysaccharide degradation based primarily on $100{ }^{\circ} \mathrm{C}$ or less temperatures to evaluate processes of degradation, kinetics of degradation, and interactions between structural composition and environment [59-63].

The polysaccharides do not convert into acids at low temperatures, while in an alkaline solution, both the starch and cellulose thermochemically degrade to water-soluble compounds $[64,65]$. These properties support the colon-targeted release of the cargo drug molecules and prevent their premature release in the acidic $\mathrm{pH}$ of the stomach [66].

Mainly, the alkaline degradation of starch provides products such as starch and cellulose, in addition to small organic compounds such as acetic acid, formic acid, lactic acid, glycolic acid, 2-hydroxyvaleric acid, and 2-hydroxybutyric acid. The second-order kinetics with the Arrhenius equation for reactivating energy of $165 \mathrm{kJmol}^{-1}$ explains the decay of starch and cellulose in alkaline solution [67]. The thermal decomposition investigations of polysaccharides calculated utilizing a slit viscometer for sodium alginate, carrageenan, and carboxymethyl 
cellulose (CMC) was reported with results indicating alginate to be much less robust than CMC and carrageenan [68-69]. The activation energy for carrageenan reportedly appeared as $104 \mathrm{kJmol}^{-1}$, while alginate displayed $50.7 \mathrm{kJmol}^{-1}$ activation energy, with $\mathrm{CMC}$ to be $79.9 \mathrm{kJmol}^{-1}$ [70].

\section{Biotolerance}

A major attribute to PS-based nanomaterials, in addition to their biocompatibility, is their physiological tolerance towards the live cells. Polysaccharides reportedly exhibit strong propensity to aggregate based on the concentration of hydroxyl or amino groups involved in hydrogen bonding within the macromolecules. The reversible interactions primarily happen at increased concentrations of the polysaccharide and decreases again after the sample dilution. Further, the polyelectrolyte concentration significantly effects the multilayered structure and the density of the polysaccharide materials. Reportedly, the polysaccharide concentrations between $0.1 \%$ and $0.5 \%$ play a significant role in the construction of multilayered structures [71-75]. The charge on polysaccharide surface determine the aggregation of their colloidal solutions where different surface charges are liable for multiple polysaccharide behaviors. The $\mathrm{pH}$ and the ionic intensity of the media further influence ionization levels of the polysaccharides, and hence the complex formation and phase segregation of low polyelectrolytes are generally associated with polysaccharide-based nanomaterials [76].

\subsection{Effect of $p H$}

Within the last few decades, the $\mathrm{pH}$-dependent swelling-shrinking induced behavior resulted in the formation of new polysaccharide NPs that received significant interest in drug delivery [77,78]. The stimuliresponsive therapeutics release rely on different interactions induced by the aqueous property, polymeric backbone, and pharmaceutical structural composition [79-82]. Researchers, therefore, evaluated the swelling behavior of polysaccharide NPs in buffer solutions of various $\mathrm{pH}$ values and reported that the swelling efficiency increased with $\mathrm{pH}$ value, indicating clearly that polysaccharides NPs present a good candidature for a drug carrier with the ability to sense variation in surrounding $\mathrm{pH}$. Several polysaccharides exhibit an outstanding tolerance towards wide $\mathrm{pH}$ conditions, salt concentrations, while displaying an excellent thermal stability [83]. Depending on the gastrointestinal (GI) secretions, the rationally designed sustained-release formulations of polysaccharides depend on $\mathrm{pH}$ of the environment, and cationic charge [84-85]. As such, the carboxy groups present on the polysaccharide offered $\mathrm{pH}$-sensitivity to the dextran-based NPs. Zhang and coworkers documented unique $\mathrm{pH}$ - and aqueous-force-sensitive hydrogel membranes wherein $\mathrm{pH}$-dependent swelling appeared in the acidic side chains of the polysaccharides [86-87]. More recently, by grafting synthetic poly(acrylic acid) copolymer (D-A copolymer) on dextran, the researchers designed an altered copolymer that displayed biotolerance, biodegradability, biocompatibility and pH-sensitivity. This polysaccharide-based system effectively delivered Ibuprofen in the phosphate buffer solution (PBS) at $\mathrm{pH} 2.0$ and $\mathrm{pH}$ 7.4. The findings further indicated the $\mathrm{pH}$-responsiveness of copolymer, which enhanced with increase in the molar ratio of AA/dextran [88].

\subsection{Effect of ionic strength}

Another variable that affects the particle size is the ionic strength of the solvent and the concentration gradient that plays a significant role in designing the materials with drug delivery applications [89]. The alternative crystalline structure and amorphous cellulose structure (contributing to stability and plasticity) offer a lower rigidity to the resulting nanofibrils at high ionic strength [90]. At moderate ionic strength, the polysaccharides-based nanomaterials promote stem cell replication without inducing cytotoxicity or inflammatory effects in vivo
[91]. Polysaccharide based nanomaterials are often responsible for in vitro anti-inflammatory effects on human keratinocytes [92]. One of the critical elements to evaluate the tolerance of the immune system towards polysaccharide-based drug delivery systems is through the evaluation of dendritic cells (DCs), which are the central inherent immune cells that regulate the immune response to specific nanomaterials [93]. DCs can also promote immune resistance by producing ILT 3, ILT4, indoleamine-dioxygenase (IDO)-1, and cytokine IL-10. Inflammatory and regulatory populations of $\mathrm{T}$ cells may also contribute to the regulation of inflammatory diseases. The DCS are the primary goal in diagnosis with tumors, infectious disorders, persistent inflammatory problems, implant recognition, and wound repair [94-96]. The polysaccharide-based nanomaterials reportedly induce adequate immune tolerance by recruiting the differential human DCs that can downregulate Th1 and Th17 cells and up-regulate Th2 and Treg in vitro [97-99].

\section{Theranostics}

The application of biodegradable polysaccharides for an effective drug delivery and bioimaging of the drug activity in the target morbid tissues is becoming rapidly desirable. The biodegradable natural polymers based on polysaccharides present extensive applications as tablet binders and viscosity liquid or emulsifying agents. The polysaccharides used as coating agents ensure the avoidance of an undesirable product flavor, enhancement in medication safety as well as improvements in pharmaceutical volume, and release rate [100]. The short half-life of deliberated pharmaceuticals requires multiple injections or doses, which continues to raise adverse effects and medication expenses. In the case of poor patient adherence, multiple dosing is also problematic. To solve these issues, the process of drug delivery to patients improved by adding biodegradable polymers for medication encapsulation [101]. The crosslinking of the cargo pharmaceutical with biodegradable polymer releases on a continuous or regulated basis from the encapsulating polysaccharide. Mainly, the extent of crosslinking in the encapsulating polysaccharide material determines the release profile of cargo drug molecules. The placement of the cargo pharmaceutical into a hydrogel such as CMC polymer generates several pores created by hydrolysis and other ways of degradation, which allows a controlled release of the cargo drug [102].

\subsection{Polysaccharide-based contrast agent}

For engineered polysaccharide-based NPs as theranostic nanomaterials, the efficacy depends on the route of operation, retention period and the form of imaging and therapy. The selected polysaccharides and their key characteristics, including the size, and structure poses a significant impact on the theranostic applications. The amphiphilic polysaccharides containing stimuli-labile linkers or hydrophobic moieties serve as a useful theranostic material [103]. Bioreducible disulfide connectivity cleavable in the intracellular environment prepared by chemical modification of Carboxymethyl dextran (CMD) to lithocholic acid presented interesting theranostic applications [104]. In another study, doxorubicin released in PBS with $10 \mathrm{~mm}$ of glutathione, a tripeptide that intracellularly reduces disulfide bond in selective and robust polynomial nanomaterials [105]. The reported nanomaterial improved the biodistribution of the cargo drug in tumor cells as indicated in the labelling experiments. As a result, antitumor efficacy in vivo of DOX-loaded NPs was considerably higher in comparison to reduction-insensitive NPs of CMD [106]. Furthermore, cucurbit [6] uril-conjugated to (CB [6]-hyaluronate) was developed as a model of the desired imaging system (Jung, Park et al. 2011). The decoration of this complex framework with FITC-spermidine (spmd) and/or the formyl-peptide receptor-like 1 (FPRL1) resulted in the formation of (FITC-spmd and/or peptide-spmd)@CB[6]-HA nanosystem used effectively to image its target-specific delivery in human breast 
adenocarcinoma cells (FPRL1 / MCF-7) with elevated $\mathrm{Ca}^{2+}$ and phosphorus-extracellular signal-regulating kinase (pERK) [107]. Qu et al. reported advanced delivery system based on the nanocellulosecontaining microparticles that offered ROS-trigger release of doxorubicin. The microparticles consisted of light-sensitive shell containing Indocyanine green, which generated ROS on near infrared laser irradiation, eventually causing the degradation of cellulose nanocrystals present in the microparticles [108]. This bioinspired system based on ROS-mediated wood degradation by brown-rot fungi possessed minimal toxicity and non-immunogenicity that further validated its drug delivery applications. Further advancements led to Gas-shearing fabrication of multicompartmental microspheres obtained from water-soluble cellulose acetate, ethyl-cellulose, and cellulose-acetate-phthalate. The utility of biodegradable polysaccharides instead of the oils and surfactants for the generation of monodisperse multicompartmental microspheres led to the achievement of cytocompatibility by the microparticles. In addition, the oil-free gas-shearing process allowed the design of microparticles up to eight compartments with a precise control over the properties of each of these compartments. These microspheres offered applications in biomedical engineering due to their ability to carry multiple materials in separate phases. These microparticles presented applications as multidrug delivery vehicles, multitarget detection, multienzyme tandem reactions, and in cell culturing technologies. The robust candidature of these microparticles in tissue engineering resolves the key challenges associated with cellular delivery in the current bioengineering paradigm [109]. The recent fabrication of coaxial electrospun core-shell fibers based on cellulose acetate offer a sustained release of the biological compounds necessary for promoting plant growth, and promote tissue healing in plants. The impregnation of these fibers with polyurethane provides mechanical strength and enhances the modulus of elasticity that further result in the development of plant wound dressings. Initially, the core-shell fibers displayed $50 \%$ release of the encapsulated material in $72 \mathrm{~h}$, followed by a slower release that occurred mainly due to the hydrophobic nature of cellulose acetate. This release profile however discouraged the sustained release application of core shell fibers. The hydrophilicity of cellulose acetate and hydrophobicity of coaxial polyurethane caused the loading of cargo drug in the latter due to the poor affinity of the drug with water. Notably, the encapsulated drug displayed two-stage release kinetics from the cellulose acetate-polyurethane coaxial electrospun fibers [110].

Superparamagnetic iron oxide nanoparticles possess characteristic magnetic properties for bioimaging applications. Their coating with polysaccharides provide robust drug delivery materials with theranostic applications [111,112]. Furthermore, as an innovative method for achieving a controlled drug delivery and bioimaging applications, superparamagnetic iron oxide nanoparticles coated with hyaluronan (HA) (HA-FeO). The target cancer cells rapidly uptake HA-FeO nanosystem on incubation for $24 \mathrm{~h}$ [113], and HA-FeO internalization into the cancerous cells was far higher than NPs without HA fabrication. Notably, the high magnetic relaxation and increased utilization of HA$\mathrm{FeO}$ promote cancerous cell imaging. The anchoring of DOX via an acid-responsive linker to the NPs further promoted a controlled release of the drug. DOX-HA-FeO system was far more potent than free DOX in offering therapeutic properties against the multidrug-resistant cancer cells [114]. Choi et al., identified the simultaneous delivery platform for the gene/drug, and tumor by using chitosan functionalized magnetic graphene (CMG). The nanosystem provided a robust candidature as $T_{2}$ contrast-improving agent as indicated by the phantom tube experiments and ex vivo MRI. As measured by the WST method, CMGs concentrated mostly on the tumor cells, as demonstrated by distribution studies and MRI [115]. Heparin-folic-IR-780 (HF-IR-780) multifunctional NPs synthesized by self-assembly through an ultrasonic sound method specifically targeted the tumor cells while providing the bioimaging applications. Assays on in vitro cell viability and photothermal in vivo therapy show a mixture of HF-IR-780 NPs with $808 \mathrm{~nm}$ laser radiation in the shape of MCF-7 or xenograft MCF-6 cell tumors [116]. Glycolated chitosan based Bcl-2 siRNA complex provided applications in gene therapy in addition to providing theranostic applications for the imaging of solid tumors. Further, the polysaccharide-based nanomaterial assisted the targeted delivery of doxorubicin to the target cancer cells [117].

\subsection{Polysaccharide-based drug delivery systems}

The differential $\mathrm{pH}$ gradient between the tumor and healthy tissues, as well as between cytoplasm and endosome serves as essential stimuli for smart drug delivery applications. The four specific approaches utilized to design the pharmaceutical carriers include drug conjugated to the polysaccharide, entrapment of therapeutics through in aerogels and hydrogels, formulation of drug-loaded polysaccharide nanoparticles (NPs) through the self-assembly. Fig. 1 highlights the various types of interactions between the drug molecule and polysaccharides. (See Table 1.)

\section{Modification of polysaccharides}

\subsection{Physical interactions}

Polysaccharide molecule containing functional head groups on their surface undergoe chemical modification for conjugating with the desired drug molecules [118]. Specifically, the $-\mathrm{OH}$ group present on the polysaccharide undergoes esterification or etherification with acylating and alkylating agents respectively [119-120]. This group undergoes further oxidation to $-\mathrm{COOH}$ and $-\mathrm{CHO}$ groups in the presence of a suitable oxidizing agent that further extends the chances of conjugation with a diverse range of functional groups on the cargo molecule. The $-\mathrm{COOH}$ group and $-\mathrm{NH}_{2}$ functionalities in polysaccharides undergo amidation, hydrazone formation, and Schiff base modification to conjugate with the cargo drug molecules [121-123]. Typically, the formation of polysaccharide gel requires a chemical or physical crosslinking of the polysaccharide for encapsulating the therapeutic molecules [124-127]. Mainly, the physical cross-linking of polysaccharides involves simpler preparation protocols devoid of chemical reagents [128]. The polysaccharides containing $-\mathrm{COOH}$ or $-\mathrm{NH}_{2}$ groups reportedly undergo ion complexation to generate the physically crosslinked nanohydrogels with myriad applications as drug delivery vehicles [129]. Typically, the anionic polysaccharides generate hydrogels by interacting with metal cations, while the cationic polyglucosamines interact with multivalent metal anions [130-131]. Similarly, the negatively charged alginic acid displays cross-linking interactions with $\mathrm{CaCl}_{2}$, whereas the positively charged chitosan readily interacts with sodium tri-polyphosphate [132-134]. Notably, the carrageenan polysaccharides contain sulfonate group along their backbone that serve as a site for cross-linking with metal ions as well as cationic polymers such as chitosan [135-137].

The interactions between the dissimilarly charged polymers result in the formation of polyelectrolyte complex [138]. Mainly, the ionic interactions in the polyelectrolytes exhibit a superior strength compared to the van der Waals forces and hydrogen bonding interactions [139]. The negatively charged polysaccharides including hyaluronic acid, pectin, xanthan, carboxymethyl cellulose, alginic acid, and chondroitin sulfate form the polyelectrolytes [140-142]. In addition, the proteins such as albumin, gelatin, collagen, keratin, and synthetic polyacrylic acids reportedly generate polyelectrolytes [143].

Hydrophobic interactions result in the physical cross-linking of polysaccharides for maintaining the structure and morphology. The anchoring of hydrophobic groups to the polysaccharide chain lower the water solubility and promote hydrophobic drug delivery [144]. The amphiphilic copolymers prepared by entrenching the hydrophilic polymeric backbone with hydrophobic structures, orient themselves to achieve a minimum free energy state, while the hydrophobic portion disengage from the aqueous environment thereby forming core shell structure of polymeric micelles [145]. The structures containing 
A



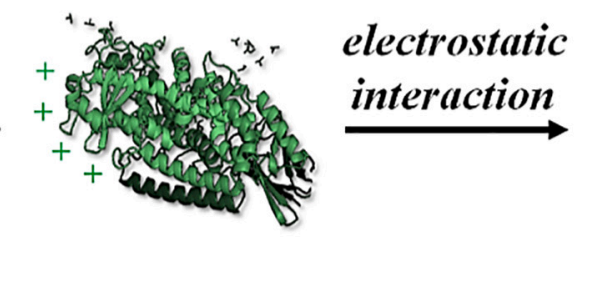
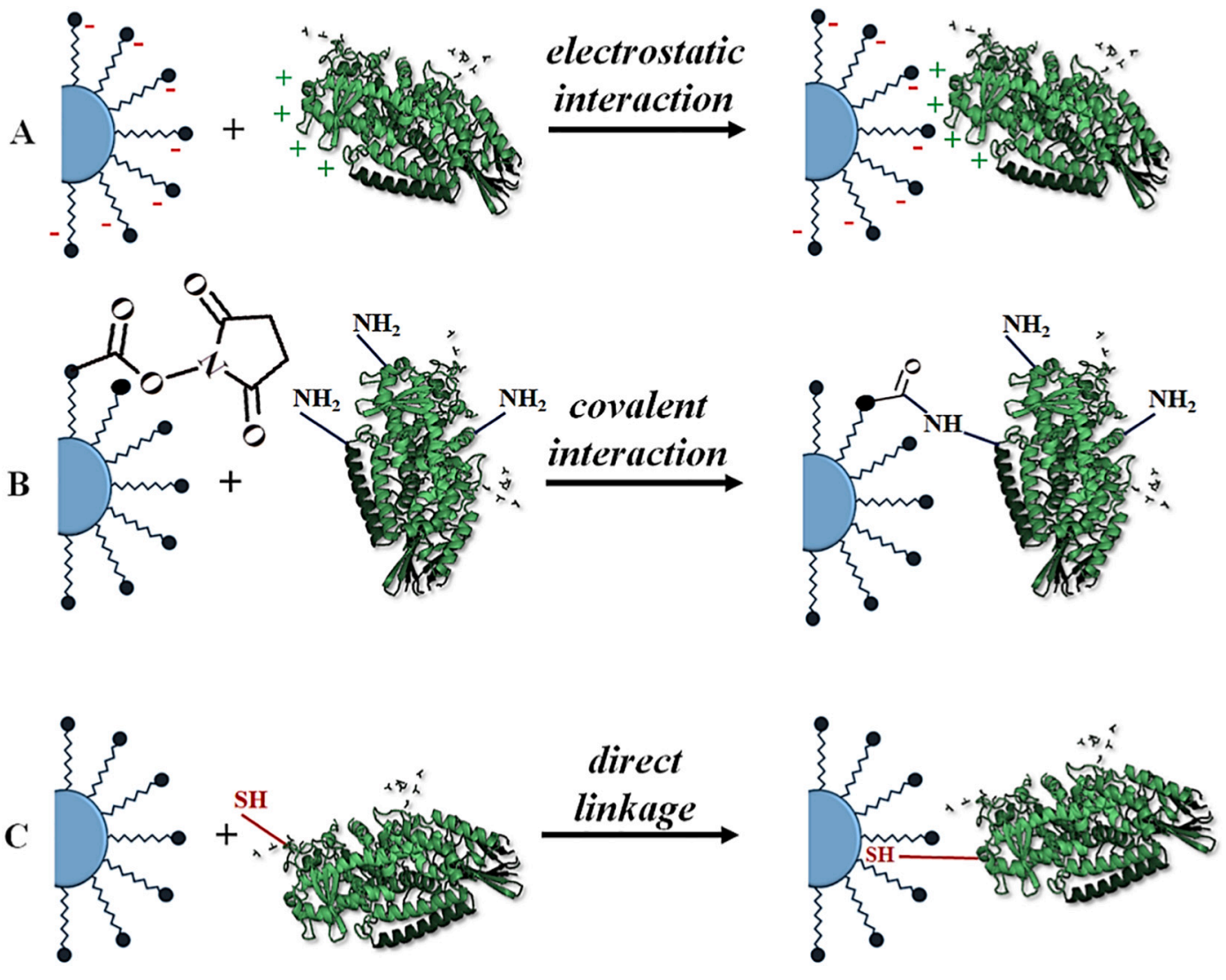

Fig. 1. The types of interactions between the polysaccharides and drug molecules.

hydrophilic outer shell enclosing the hydrophobic interior serve as carrier for hydrophobic drug molecules [146]. The modification of polysaccharides with long chain fatty acids such as palmitic acid, stearic acid, linoleic acid, linolenic acid, and hexanoic acid result in the generation of polymeric micelles [147-148]. Similarly, the conjugation of polysaccharides to hydrophobic polymers such as poly (ecaprolactone), poly (isobutyl cyanoacrylate), poly (ethylene glycol) derivatives, and pluronic copolymers generated the desired core-shell drug delivery systems with hydrophobic core and hydrophilic shell [149]. Nevertheless, the presence of polar groups such as $-\mathrm{OH},-\mathrm{COOH},-\mathrm{NH}_{2}$ in polysaccharides participate in hydrogen bonding interactions that play a critical role in drug delivery applications. The polysaccharides such as chitosan forms hydrogen bonds at $\mathrm{pH}>5$, whereas it requires low temperature and $\mathrm{pH}$ to form hydrogen bonding in agarose [150]. Similarly, the synthetic polysaccharide carboxymethyl cellulose demonstrates $\mathrm{pH}$ sensitive hydrogen bonding interactions, which form the basis of drug delivery applications in these polymeric systems [151].

\subsection{Chemical modifications}

The chemical modification of polysaccharides led to their conjugation with drug molecules via functional head groups through the covalent bonds. These chemical modifications followed by a subsequent conjugation mainly occur via nucleophilic replacement of the saccharide oxygen by heteroatomic nucleophiles. Typically, a saccharide electrophile possesses lower reactivity towards the nucleophilic substitution compared to the other hydrocarbon-derived molecules [152]. The destabilization of carbocation generated at the primary or secondary position due to the presence of surrounding electron withdrawing $-\mathrm{OH}$ groups increases the difficulty of SN1 reaction at the primary and secondary positions, as compared to the SN2 reactions at the same position [153].

The bulkiness of the alkoxy and acyloxy substituents further lower the reactivity of saccharide- derived electrophiles towards SN2 reactions [154]. Especially, the higher stability of the chair conformation of the six-membered saccharide ring and the presence of multiple equatorial substituents makes it difficult for the completion of an SN2 attack the secondary position of the target saccharide [155]. Mechanistically, the formation of SN2 transition state involves changes in the ring conformation for accommodating the attacking nucleophile, and the leaving group around the central carbon. However, the highly stabilized chair conformation refuses to undergo these conformational changes as it results in less favored strained conformation [156].

The replacement of primary and secondary $-\mathrm{OH}$ groups in saccharide molecules with a good leaving group improves the susceptibility of electrophilic carbon towards the nucleophilic attack. Mainly, the halide ions, and the less reactive functional groups such as phosphonate and sulfonate prove better leaving groups at the primary position. While the groups such as triflates and epoxides serve as better leaving groups at the secondary position. The nucleophilic reaction by a saccharide nucleophile through the ' $\mathrm{O}$ ' atom result in the acylation or alkylation of the polysaccharide, whereas the nucleophilic attack on polysaccharide molecules by alcohols or carboxylates for the formation of ether and esters occur less commonly [157]. The esterification of polysaccharides occurs preferably via Mitsunobu reaction, which incorporates an in situ activation of the -OH group by phosphonium leaving group, where the attacking nucleophile facilitates its departure [158]. The high-yielding, regioselective Mitsunobu reactions mainly occur at the primary position of unprotected saccharide units [159]. Amine group acts as neutral nucleophile for modifying the polysaccharide with alkyl chains. Preferably, the monovalent properties of the azide nucleophiles prevent the multiple side reactions or cross linking of the parent polysaccharide. The azide functionalization of polysaccharides proves highly beneficial for their click conjugation to the drug molecules or biomolecules bearing a propargyl substituent [160]. The click conjugation of polysaccharides with desirable drug molecules via strong triazole spacer improves the in 
Table 1

Polyaccharides in drug delivery applications.

\begin{tabular}{|c|c|c|c|c|c|}
\hline PS-based polymer & $\begin{array}{l}\text { Therapeutic agents \& type of } \\
\text { targeting }\end{array}$ & Cell types & $\begin{array}{l}\text { Model of } \\
\text { study }\end{array}$ & Polymer advantages & References \\
\hline Dextran & COX-2 siRNA/ Passive & $\begin{array}{l}\text { Breast cancer cell lines (MDA- } \\
\text { MB231) }\end{array}$ & $\begin{array}{l}\text { In vitro } \\
\text { and in } \\
\text { vivo }\end{array}$ & $\begin{array}{l}\text { Biocompatible, pH stimuli-responsive, down- } \\
\text { regulate Cyclooxygenase COX-2 genes in tumor } \\
\text { cells }\end{array}$ & [215] \\
\hline Dextran-folic acid & DOX/Active & Breast cancer cell line (4 T1) & $\begin{array}{l}\text { In vitro } \\
\text { and in } \\
\text { vivo }\end{array}$ & $\begin{array}{l}\text { Reducing the side effect of DOX, enhanced tumor } \\
\text { growth inhibition, and prolonged survival rate }\end{array}$ & [216] \\
\hline Dextran- Indomethacin & Paclitaxel/ Passive & $\begin{array}{l}\text { Breast cancer cell line (MCF- } \\
\text { 7) }\end{array}$ & $\begin{array}{l}\text { In vitro } \\
\text { and in } \\
\text { vivo }\end{array}$ & $\begin{array}{l}\text { Enhanced cellular uptake, prolonged } \\
\text { pharmacokinetics (prolonged circulation time } \\
\text { and slower elimination), enhanced tumor growth } \\
\text { inhibition }\end{array}$ & [216] \\
\hline Dextran-albumin & Paclitaxel/ Passive & Colorectal cell line (CT-26) & $\begin{array}{l}\text { In vitro } \\
\text { and in } \\
\text { vivo }\end{array}$ & $\begin{array}{l}\text { Cellular proliferation enhanced inhibition, } \\
\text { inducing apoptosis, Enhanced drug circulation } \\
\text { times }\end{array}$ & {$[217]$} \\
\hline Dextran-folic acid & Resveratrol/ Active & Lung cell line (A549) & In vivo & Enhanced cellular apoptosis and drug intake & [218] \\
\hline Dextran-DOX & Doxorubicin/ Passive & Lymphoma cell lines & $\begin{array}{l}\text { In vitro } \\
\text { and in } \\
\text { vivo }\end{array}$ & $\begin{array}{l}\text { Reduced cytotoxicity (cardiac), enhanced } \\
\text { apoptosis, enhanced intracellular intake leading } \\
\text { to increased DOX concentration that inhibits } \\
\text { tumor growth }\end{array}$ & [219] \\
\hline Hyaluronic acid- Chitosan & 5-Fluorouracil/ Active & $\begin{array}{l}\text { Lung cell line (A549) \& liver } \\
\text { cell line (HepG2) }\end{array}$ & In vitro & $\begin{array}{l}\text { Enhanced cell apoptosis and cellular drug } \\
\text { accumulation }\end{array}$ & [220] \\
\hline $\begin{array}{l}\text { Hyaluronic acid- Poly-lactic-co- } \\
\text { glycolic acid; }\end{array}$ & Paclitaxel \& curcumin /Active & $\begin{array}{l}\text { Breast cancer cell line (MCF- } \\
\text { 7) }\end{array}$ & $\begin{array}{l}\text { In vitro } \\
\text { and in } \\
\text { vivo }\end{array}$ & $\begin{array}{l}\text { Prolonged pharmacokinetics, Enhanced cellular } \\
\text { accumulation }\end{array}$ & [221] \\
\hline $\begin{array}{l}\text { Hyaluronic acid- Poly-lactic- } \\
\text { co-glycolic acid; }\end{array}$ & Paclitaxel/Active & $\begin{array}{l}\text { Breast cancer cell line (MDA- } \\
\text { MB-231) }\end{array}$ & In vitro & Decreased the IC50 of paclitaxel significantly & [73] \\
\hline $\begin{array}{l}\text { Hyaluronic acid- Poly- } \\
\varepsilon \text {-caprolactone-Chitosan }\end{array}$ & Naringenin/Active & Lung cancer cell line (A549) & $\begin{array}{l}\text { In vitro } \\
\text { and in } \\
\text { vivo }\end{array}$ & $\begin{array}{l}\text { Enhanced cell apoptosis, increased drug intake } \\
\text { resulting in inhibiting cancer growth }\end{array}$ & [222] \\
\hline Hyaluronic acid-Silica & Paclitaxel/Active & $\begin{array}{l}\text { Breast cancer cell line (MCF- } \\
\text { 7) }\end{array}$ & $\begin{array}{l}\text { In vitro } \\
\text { and in } \\
\text { vivo }\end{array}$ & $\begin{array}{l}\text { Enhanced cancer growth suppression, increased } \\
\text { intake and drug accumulation }\end{array}$ & [223] \\
\hline Hyaluronic acid & $\begin{array}{l}\text { Doxorubicin \& Gemcitabine } \\
\text { /Active }\end{array}$ & $\begin{array}{l}\text { Breast cancer cell lines (MDA- } \\
\text { MB-231 \& } 4 \text { T1) }\end{array}$ & $\begin{array}{l}\text { In vitro } \\
\text { and in } \\
\text { vivo }\end{array}$ & $\begin{array}{l}\text { Dual modality drug delivery system, enhanced } \\
\text { inhibition to cancer growth }\end{array}$ & {$[224]$} \\
\hline $\begin{array}{l}\text { Hyaluronic acid- } \\
\text { Polyamidoamine }\end{array}$ & $\begin{array}{l}\text { Doxorubicin \& Cisplatin } \\
\text { /Active }\end{array}$ & $\begin{array}{l}\text { Breast cancer cell lines (MDA- } \\
\text { MB231 \& MCF-7) }\end{array}$ & $\begin{array}{l}\text { In vitro } \\
\text { and in } \\
\text { vivo }\end{array}$ & $\begin{array}{l}\text { Tumor growth inhibitor at low drug } \\
\text { concentrations }\end{array}$ & {$[225]$} \\
\hline $\begin{array}{l}\text { Hyaluronic acid-Silica- } \\
\text { polyethyleneimine }\end{array}$ & $\begin{array}{l}\text { TWIST- siRNAs (Basic helix- } \\
\text { loop-helix transcription } \\
\text { factors)/ Active }\end{array}$ & $\begin{array}{l}\text { Ovarian cancer cell line } \\
\text { (Ovcar-8) }\end{array}$ & $\begin{array}{l}\text { In vitro } \\
\text { and in } \\
\text { vivo }\end{array}$ & $\begin{array}{l}\text { Reduced cancer growth and cell survival through } \\
\text { selective targeting }\end{array}$ & [226] \\
\hline Hyaluronic acid-Silica & 5-Fluorouracil /Active & Colon cancer cell line (HT29) & $\begin{array}{l}\text { In vitro } \\
\text { and in } \\
\text { vivo }\end{array}$ & $\begin{array}{l}\text { Tumor repression, high cytotoxicity and high } \\
\text { accumulation in the tumor through selective } \\
\text { targeting }\end{array}$ & {$[227]$} \\
\hline $\begin{array}{l}\text { Chitosan- } N \text {-acetyl histidine } \\
\text { and arginine }\end{array}$ & DOX/Passive & Breast cancer cell lines MCF-7 & In vitro & Enhanced cytotoxicity and cellular uptake & [228] \\
\hline Chitosan- Trimethyl and folate & DOX \& IL-2/Active & $\begin{array}{l}\text { Lung cancer cell line (A549), } \\
\text { Liver cell line (SMMC-7721) } \\
\text { and hepatoma cell line (H22) }\end{array}$ & $\begin{array}{l}\text { In vitro } \\
\text { and in } \\
\text { vivo }\end{array}$ & $\begin{array}{l}\text { Increase IgG expression levels, Increased } \\
\text { cytotoxic T lymphocytes }\end{array}$ & [229] \\
\hline Chitosan & Suramin and DOX/ Passive & $\begin{array}{l}\text { Breast cancer cell line (MDA- } \\
\text { MB231) }\end{array}$ & $\begin{array}{l}\text { In vitro } \\
\text { and in } \\
\text { vivo }\end{array}$ & Inhibit Breast and lung metastasis & {$[230]$} \\
\hline $\begin{array}{l}\text { Chitosan- } \\
\text { Carboxymethyldextran }\end{array}$ & $\begin{array}{l}\text { DOX and IL17RB siRNA/ } \\
\text { Passive }\end{array}$ & $\begin{array}{l}\text { Breast cancer cell line (MDA- } \\
\text { MB361) }\end{array}$ & In vitro & $\begin{array}{l}\text { Decrease tumor cellular viability, inhibits growth, } \\
\text { tumor cells migration, and proliferation }\end{array}$ & {$[231]$} \\
\hline $\begin{array}{l}\text { Chitosan- Hyaluronic acid- } \\
\text { sulfobutyl-ether- } \\
\beta \text {-cyclodextrin }\end{array}$ & Curcumin/Passive & Colon cancer cell line (HT29) & In vitro & $\begin{array}{l}\text { Enhanced cellular uptake, reduced cellular } \\
\text { proliferation, and high toxicity }\end{array}$ & [232] \\
\hline Alginate & DOX/Passive & Melanoma cell line (B16) & $\begin{array}{l}\text { In vitro } \\
\text { and in } \\
\text { vivo }\end{array}$ & $\begin{array}{l}\text { Inhibit tumor growth, higher cellular uptake, high } \\
\text { cytotoxicity }\end{array}$ & [233] \\
\hline Alginate & $\begin{array}{l}\text { Gold NPs (AuNPs) \& } \\
\text { cisplatin/ Passive }\end{array}$ & Colon cancer cell line (CT26) & $\begin{array}{l}\text { In vitro } \\
\text { and in } \\
\text { vivo }\end{array}$ & Tumor growth high inhibition, enhanced survival & [234] \\
\hline Alginate & Paclitaxel/Passive & $\begin{array}{l}\text { Different breast cancer cell } \\
\text { lines }\end{array}$ & $\begin{array}{l}\text { In vitro } \\
\text { and in } \\
\text { vivo }\end{array}$ & $\begin{array}{l}\text { Promote cell cycle arrest, induce apoptosis and } \\
\text { reduce the bioavailability }\end{array}$ & [235] \\
\hline Alginate-chitosan & DOX/Active & $\begin{array}{l}\text { Breast cancer cell line (MCF- } \\
\text { 7) }\end{array}$ & In vitro & Inhibit tumor progression and cellular growth & [236] \\
\hline Pullulan & $\begin{array}{l}\text { Floate \& Polyethylenimine/ } \\
\text { Active }\end{array}$ & $\begin{array}{l}\text { Cervical (Hela) and liver } \\
\text { (HepG2) }\end{array}$ & $\begin{array}{l}\text { In vitro } \\
\text { and in } \\
\text { vivo }\end{array}$ & Tumor growth inhibition & [237] \\
\hline Pullulan- Folate & Paclitaxel/Active & $\begin{array}{l}\text { Liver cancer cell line (SMMC- } \\
\text { 7721) }\end{array}$ & $\begin{array}{l}\text { In vitro } \\
\text { and in } \\
\text { vivo }\end{array}$ & $\begin{array}{l}\text { Lower cytotoxicity due to selective targeting and } \\
\text { prolonged release }\end{array}$ & [238] \\
\hline
\end{tabular}


vivo stability and the pharmacokinetics of the drug delivery system [161-162]. Particularly, the click conjugation presents extensive applications in molecular medicine where the cargo therapeutics bind with desired biomolecules including polysaccharides, antigens, nucleic acid sequence, mRNA, and peptides [163]. Likewise, the thiols participate in nucleophilic substitution with polysaccharide rings that contain halides as leaving group.

Fig. 2 illustrates the various chemical modifications done on polysaccharides at the free $-\mathrm{OH}$, and $-\mathrm{COOH}$ groups. The oxidation of polysaccharides at the $-\mathrm{OH}$ groups on $\mathrm{C} 2$ / $\mathrm{C} 3$ position to yield aldehyde groups causes a faster degradation in physiological background when used as controlled drug delivery carriers. The conversion of hydroxyl substituent to aldehyde groups provide a rotational freedom to the parent saccharide units, however it requires precautions such as light exclusion to prevent the occurrence of any side-reactions, in addition to limiting the concentration of the oxidant in order to achieve a controlled oxidation of alginate [164]. Notably, the oxidized polysaccharide completely degrades at the physiological $\mathrm{pH}=7.4$ at $37^{\circ} \mathrm{C}$, thereby making it an excellent drug delivery carrier [165]. The oxidation of polysaccharide units results in the formation of reactive aldehyde groups, thereby encouraging further chemical modification by reductive amination. The conversion takes place in the presence of suitable reducing agents that selectively reduce the imine intermediate, over the starting aldehyde group [166]. The reductive amination of polysaccharides with long chain alkyl amines provides amphiphilic properties to the parent polysaccharide, and lower their surface tension for a better physiological absorption. This drug delivery system ensures a better loading capacity of hydrophobic drug molecules for achieving a controlled drug release profile. The structural similarity of sulfated polysaccharide with anticoagulant heparin improves the blood compatibility of the test polysaccharide deliberated for drug delivery applications [167]. The in vitro assay for appraising the coagulation of human plasma in the presence of sulfated alginates suggested notable anticoagulant properties of the polysaccharide by targeting the intrinsic coagulation pathways [168]. Similarly, the esterification of polysaccharide acids with alkyl groups improves the hydrophobicity of the parent polysaccharide. Furthermore, the synthesis of alginate bis-amides via Ugi reaction presents an important modification of polysaccharides for their drug delivery applications.

\section{Polysaccharide-drug conjugates}

Numerous natural and synthetic water-soluble polymers reportedly exhibit conjugation with therapeutic molecule through chemical conjugation [169]. Pharmacokinetic investigations of drug-conjugating polysaccharides have documented the implications of natural and sustainable polymers as robust drug delivery systems. In addition to the synthetic, water-soluble polymers, the natural polymers such as dextran, chitosan, hyaluronic acid, and cellulose seem to have a tremendous drug carrier potential [170]. Coupling of the hydrophobic doxorubicin (DOX) with the acid-cleavable hydrazone bond generated DOX-chitosan nanoconjugates with $\mathrm{pH}$-sensitive drug release [171]. The study

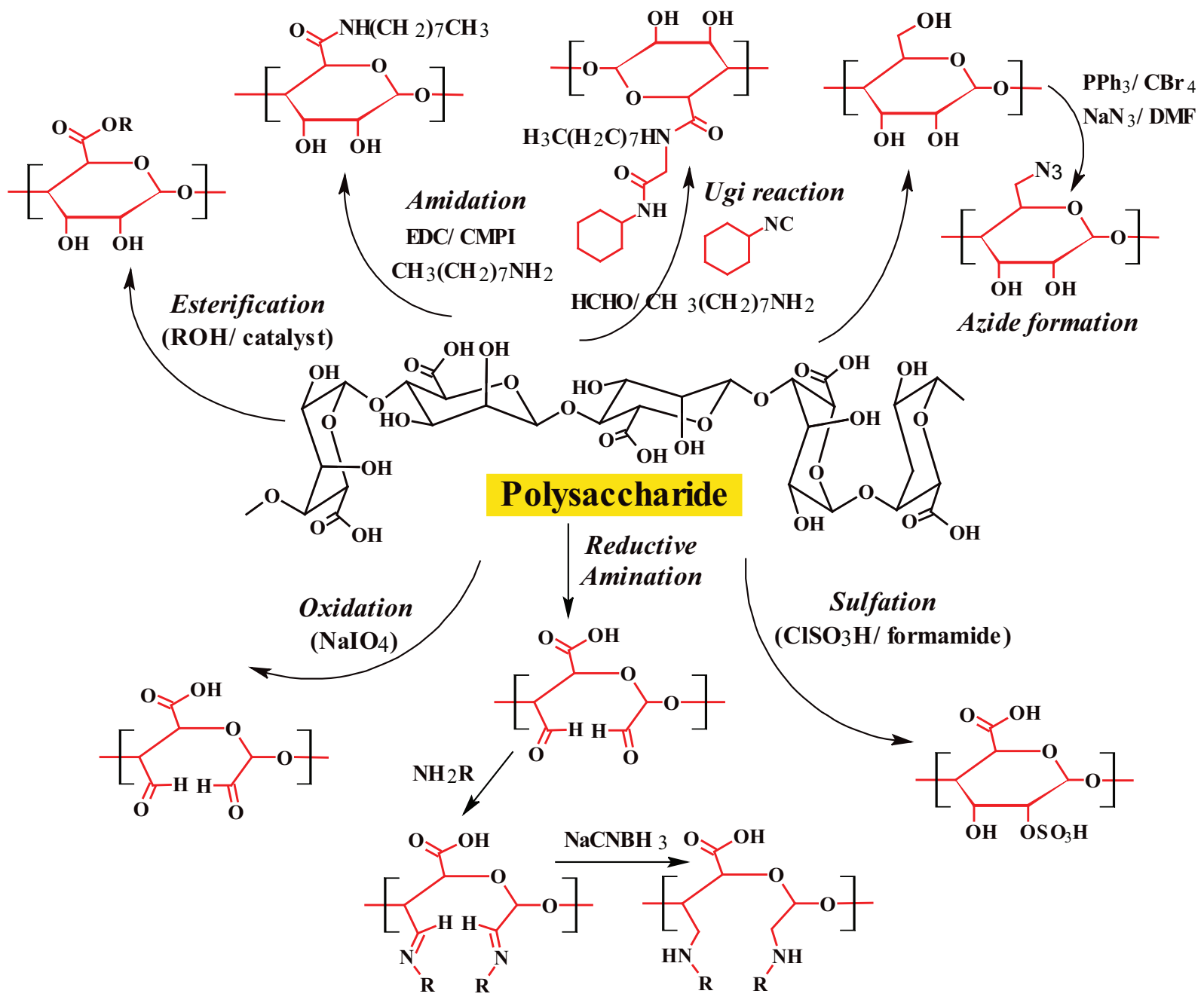

Fig. 2. Chemical modifications on polysaccharides. 
revealed that the chitosan-DOX conjugates with the acid-cleavable hydrazone bond became stable at neutral $\mathrm{pH}$ and dissolved at $\mathrm{pH}$ 5.0, which made a significant contribution to the eruption of DOX into HeLa cells. Prodrug NPs internalized rapidly to illustrate its potential applications in tumor-targeted pharmaceutical materials, contributing to a substantial accumulation and deposition of DOX in HeLa cells [172]. Simple carbohydrates, such as dextran reportedly utilize in the recombination of medications. Bacterial strains, including Leuconostoc and Streptococcus produce copious amounts of dextran polysaccharide, including the primary and secondary categories of dextran that offers possible therapeutic conjugation regions with specific methods [173-174]. Reportedly, the destroying the impact of free curcumin on cancerous cells diminishes with time, whereas the cytostatic activity effects of curcumin-loaded chitosan NPs of the same concentration range on MCF7 cells improved significantly in the incubation period. Furthermore, the chemical tailoring of such materials offered selective and more efficient drug delivery to tumors due to the predominant amine and hydroxyl groups on the chitosan framework [175]. For the delivery of paclitaxel (PTX) and docetaxel (DTX), Skorik et al. used chitosan-based NP as nanocarriers. The drug-charged succinyl and glutaryl chitosan NPs displayed a considerable cytotoxicity towards the gastrointestinal cell lines and thus increased their anticancer activity compared to free drugs. Due mainly to a tumor-homing ligand (3-carboxyphenylboronic acid), the updated carboxymethyl chitosan-based NPs loaded with DOX demonstrated an increased accumulation concentrations and penetration into tumor presenting mice with $\mathrm{H} 22$ lung metastasis. This significantly reduced the mass of the H22 metastases lung tumor by further infiltration and aggregation of NPs in the tumor site.

D-Glucuronic acid repeats and D-N-acetilglucosamin disaccharide conjugate to generate the hyaluronan (HA) by means of $\beta-1,4$ - and $\beta-1,3$ glycosidic links [176]. The hyaluronate framework comprises of hydroxy and carboxyl groups, which participate for the conjugation with several drug molecules. Considering the steric hindrance and weak carboxyl reactivity, direct conjugation could is not preferred [177-178]. HA derived products that have the functional head groups such as hydrazine $\left(-\mathrm{NH}_{2}-\mathrm{NH}_{2}-\right)$ improve the reactivity and drug conjugation efficacy. HA derivatives that require carboxylic acids to be substituted and functionalized also display increased drug loading with limited alteration in the polysaccharide structure [179]. Paclitaxel (PTX) was elevated in loading and reduced product toxicity relative to free PTX in conjugations with HA-deoxycholic acid coupled to bio-reducible cysteamine. The binding effects of the medication retains even after a significant degree of replacement. Several methods reportedly cope with the low solubility of HA in conventional organic solvents, which hampers cytotoxic conjugation reactions [180]. Those methods include the use of combinations of polar solvents with water, polyethylene dimethyl ether nanocomplexation and ion compositions of long-chain aliphatic cations [181]. The application of HA-drug conjugates offer a selective targeting of the excessive CD44 overexpressed receptors [182]. HAconjugated products, including HA-mitomycin C, HA-epirubicin, HAbutyrates, and HA-paclitaxel present robust applications in drug delivery. Notably, the inhibitor of histone deacetylase demonstrated enhanced apoptosis activity, resulting in reduced in vivo tumor load and inhibition of in vitro cell development on its conjugation with HA [183]. The usage of $\mathrm{N}, \mathrm{N}^{\prime}$-dicyclohexylcarbodiimide (DCC), and cholic acid derivatives (Colic acid) have modified sucrose and poly(d, 1-lactic-coglycolic acid) (PLSGA) through crosslink. This represents an exciting development for a controlled system of drug delivery for medications with low aqueous solubility [184]. Numerous uses featuring various composite hydrogels composed of polysaccharides including chitin, nanocellulose and chitosan offered advanced pharmaceutical delivery systems, enhanced regenerative medicine, tissue engineering, wound dressings, and water purification sorbents [185]. Chitin composites can be generated in spherical nanogels, in conjunction with rhodamine 123 dye that improved the drug distribution provides applications in tissue engineering $[186,187]$. The polysaccharides conjugated to folate, fluorescent functionalities maintain an optimal drug loading and drug release profile and present potential applications for gene therapy on specific positions, including cancerous cells [188]. Development of wound treating products based on Pectin in the recent years combined with cellulose and micro fibrillated cellulose offered promising results in vivo. The findings on animal models were encouraging, but further experimental tests were required for clinically success. Pectin presents applications in medicinal sprays as a drug carrier for the administration of drugs. The Pectin incorporated nasal spray drug such as fentanyl that relieves pain in cancer and contributes to better chemotherapy treatment [189]. Fig. 3 depicts the main strategies for drug encapsulation by polysaccharides.

\section{Drug retention in aerogel layer and hydrogels}

Hydrogels represent 3-D hydrophilic, polymeric platforms, which hold potential preserve large quantities of water or biological fluids. Aerogels are extremely porous and provide large internal surfaces with exceptional drug delivery capabilities $[190,191]$. Almost all of these gels are static and brittle; however, polysaccharides form xerogels and they tend to generate transparent hydrogels, which spontaneously shape interconnected polymers. The morphological and chemical features of a gel rely on the consistency of the formulated aerogel. For the processing and distribution of chemically stable hydrogels and aerogels, the utilization of hydrophilic polysaccharides and their precursors offer selective delivery of therapeutics [192,193]. The association of a polyelectrolyte with an opposing multivalent ion by dynamic coconservation determines the properties of ionotropic hydrogels. Hydrogels are sensitive to different environmental conditions including $\mathrm{pH}$, ionic strength, and temperature that influence their characteristics and morphology [194,195]. In certain settings, it is feasible to provide a long-lasting release for up to three months of nanofibrillar cellulose for long-term pharmaceutical applications [196]. In an attempt to improve the structural strength and the swelling-deswelling abilities of the polymer, engineered single networks to the hydrogel reduced the structural strength to obtain the interpenetrating polymer (IPNs). The IPNs constitute of the interconnecting polymer network formed by linking two different polysaccharides. In this context, gelatin-graftspolyaniline and carboxymethyl chitosan were prepared as injectable coordinating IPN hydrogels with enhanced mechanical proprieties, crosslinked in physiological terms with oxidized dextran via the Schiff base formation. The evaluation of hydrogels for in vivo biocompatibility demonstrated a tremendous potential for drug and tissue development [197]. Alginate is a charged biopolymer consisting of repetitive disaccharide units comprising of 1-4-linking $\beta$-D-mannuronic acid and $\alpha$-Lglucuronic acid organized in separate blocks or alternating blocks at different proportions. Researchers have been able to establish advanced techniques for the distribution of natural pharmaceutical medications with the use of ionic and covalent combinations to form Alginate-based gels [198]. The redox-sensitive alginate offers applications in the construction of hydrogels and nanogels using carbodiimide interconnection. Gels developed using redox-degradable polymers dissolve to release the cargo medicinal product. The poly(diallyl dimethylammonium chloride) (PDADMAC) conjugated with alginate provides temperature- and $\mathrm{pH}$ sensitive hydrogels in drug delivery applications. The $\mathrm{pH}$ behavior of the hydrogels implies total swelling at $\mathrm{pH} 4$, due to the ionization of the COOH groups in alginate, induced by electrostatic repulsion [199]. In comparison, polyelectrolyte complexes, PDADMAC coexist with ionized $\mathrm{COOH}$, resulting in a diminishing swelling ratio [200]. Alongside the swelling attribute, investigators often build a framework for the controlled released of therapeutics with other features, including superporosity and electromechanical sensitivity. Several attempts aimed at the colon-targeted delivery of rabeprazole sodium by the implementation of biodegradable polymers for its mucoadhesive properties, generated from crosslinking $O$-carboxymethyl-chitosan and carbopol 


\section{Polyelectrolyte complexes}



2. Self assembly

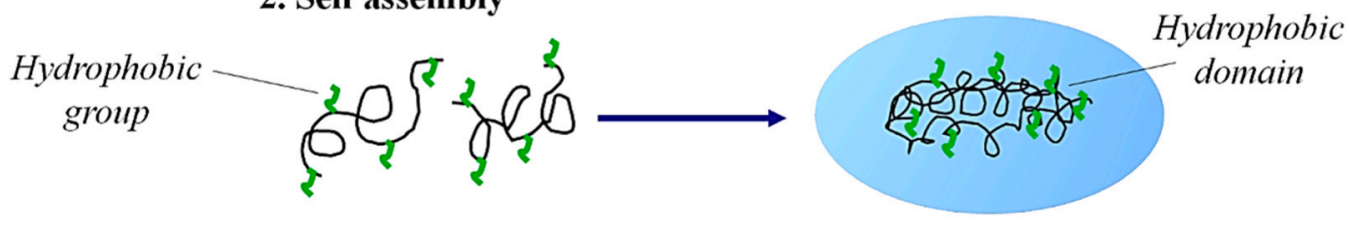

\section{Polysaccharide-drug conjugate}

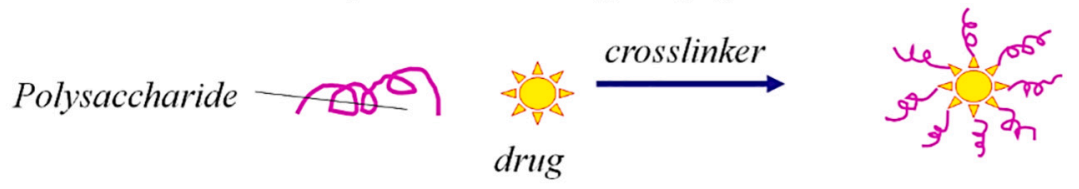

\section{Covalent crosslinkage}
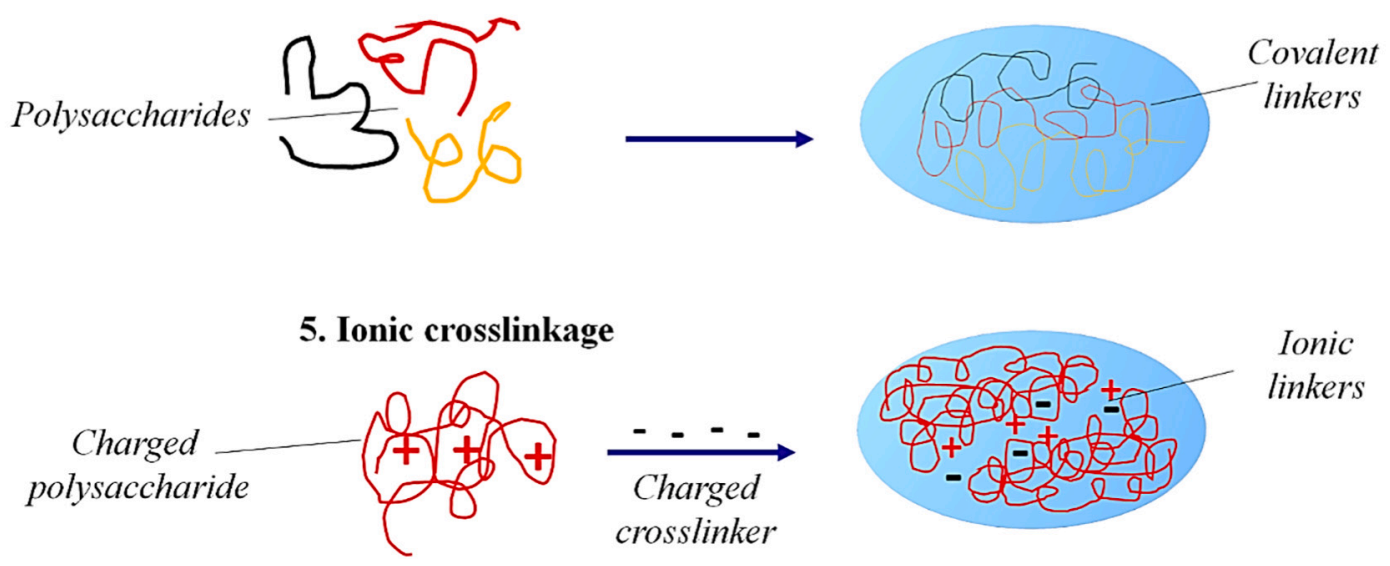

Ionic

linkers

Fig. 3. Drug loading strategies by Polysaccharide nanoparticles.

with a $\mathrm{Ca}^{2+}$ ionic cross-linking [201]. CMSP hydrogel displays the ionic crosslinking with $\mathrm{Al}^{3+}$ for colon-targeted drug delivery. A CMSP hydrogel, filled with 5-aminosalicylic acid (5-ASA), released small levels of 5-ASA at stomach $\mathrm{pH}$ and maintained the release of drugs at colonic $\mathrm{pH}$. The manufacturing of the polymer from industrial waste further promised minimization of pollutants as well as the costs of formulation [202]. Glutaraldehyde effectively controlled the release of Buflomedil hydrochloride through the Locust gum with poly(vinyl alcohol). This combination appropriately controlled the rate of release to short halflives and improved the water solubility of the encapsulated pharmaceutical items [203]. The psyllium-based polymers are other modified polysaccharides widely used in drug delivery applications. The maximum effectiveness appeared at the $\mathrm{pH} 7.4$ for the product buffer for psyllium-poly(vinyl alcohol) filled with rabeprazole sodium. The hydrogels possess hemocompatibility, which suggests their application in pharmaceutical goods for the treatment of bloating ulcers [204].

\section{Polysaccharide drug-loaded through self-assembling}

Hydrophilic polysaccharide backbones construct the self-assembling frameworks, such as niosomes and liposomes, when they are introduced to hydrophilic polymers [205-207]. The self-assembly of hydrophobic polysaccharide formulates from the polymer backbones treated with hydrophobic sections of hydrophilic polysaccharides containing hydroxy, amino or carboxy groups that eventually form amphiphilic macromolecules. This solubilizes the hydrophobic drugs molecules in the self-assembling drug delivery polysaccharides. The factors such as fluctuations in $\mathrm{pH}$, ionic intensity, and temperature further determine the drug release from these polysaccharides [208]. Self-assembled nanoparticles in hydrophilic polysaccharide frameworks such as amylose, guar gums, pectin, chitosan, dextran and rubber beans offer wider applications in the delivery of hydrophobic drugs at the target site. The polysaccharides offer an ideal platform for colon-target distribution since it shows high stability in the stomach $\mathrm{pH}$, as compared to the intestine physiological environment as the colon microbiota induces 
polysaccharide degradation and eventually release the therapeutics payload into the colon [209]. Polysaccharide-based NPs such as chitosan armed with therapies like paclitaxel, ibuprofen, and amphiphilic doxorubicin (DOX) improve the overall therapeutic effect of the drug. Amino groups on Chitosan participate in the grafting of hydrophobic groups through acylation with acyl chloride or anhydride acid and ultimately interconnected with deoxycholic acid. Advanced applications such as plasmid DNA transfection with deoxycholic groups-acid NPs $(160 \mathrm{~nm})$ was reported in COS-1 cells [210]. Dextran, often considered the selfassembled nanosized drug carrier, offers the grafting of several biomolecular moieties such as bile acids, normal amphiphilic steroids, and lauryl strands. Azido-modified dextran NPs mixed with mannose showed an improved cellular internalization for the delivery of therapeutic agents. Addition of acrylic acid to dextran generated $\mathrm{pH}$-sensitive NPs between 40 and $140 \mathrm{~nm}$ diameter [211]. The modified dextran effectively improves the absorption of DOX, hence proving to be a viable transporter for DOX. Dextrin nanogel filled with DOX minimizes the toxicity of the drug towards normal human cells by reducing the therapeutics side effects. Chemical transformation of HA to form NPs in the size range $200-400 \mathrm{~nm}$, comparable to dextran and chitosan conjugated with $5-\beta$ cholinic acid offered highly effective treatment of inactive CD44 tumors. HA shapes amphiphilic chain copolymers when covalently linked to the poly( $\gamma$-benzyl l-glutamate) component [212]. Not only were these nanoparticulates elevated the cellular uptake by endocytosis, but they have also increased drug toxicity in the target KB cells [213]. The usage of starch or cellulose-based drug delivery nanoparticles also improved their solubility in the organic solvents by the introduction of chemical modifications on the hydroxy and carboxyl groups. These approaches further improved the drug loading capacity onto these nanocarriers by conjugating with the functional head groups on the polysaccharide surface [214].

Therefore, the polysaccharide offer a fascinating choice as polymeric material in drug delivery due to biodegradability and biocompatibility. The application of polysaccharide in drug delivery is growing very fast as it provides a safe, nontoxic and tunable alternates of synthetic polymers for the same purpose. The diverse chemical structures, functional groups and physicochemical properties are making polysaccharides a suitable candidate in drug delivery [239,240].

\section{Polysaccharide based controlled release and targeted formulations}

Unlike the synthetic hydrophilic polymers, polysaccharide possess a variety of hydrophilic functional groups on its structure like $-\mathrm{OH}$, $-\mathrm{COOH}$, and $-\mathrm{NH}_{2}$ group which are responsible for water absorption and further swelling of polysaccharide. These groups grant a variety of functional capability to the polysaccharide-based systems such as bioadhesion and control release property. Controlled release property of polysaccharide-based drug delivery systems has been explored extensively for achieving a prolonged delivery of variety of therapeutics such as chemotherapeutics, proteins, peptides, nucleic acid and many more [1]. The control release of therapeutics from the swelled polysaccharide depends on the porosity or degree of swelling, further regulated by certain parameters like $\mathrm{pH}$, temperature, ionic strength and electric fields [241]. Several polysaccharides present controlled release and target specific delivery applications.

\section{Chitosan}

It is a linear polysaccharide obtained from the exoskeleton of arthropods such as crabs, lobster, and shrimp and cell walls of fungi. It is available in variety of molecular weight and degree of acetylation, which control its physical and biological property. Hydroxy and amino groups on the chitosan are involved in making intra- and intermolecular hydrogen bonds. The $\mathrm{pH}$ dependent protonation of amino group leads to swelling of the Chitosan to form three- dimension structure gel at $\mathrm{pH}$ lower than the pKa [242]. Various chitosan salts such as chitosan palmitate and chitosan laurate exhibit different degrees of swelling, and thus drug release from the variety of dosage form. The presence of primary amines in chitosan is responsible for its biological activity such as antimicrobial, anticancer. Chitosan nanoparticles showed greater antimicrobial activity against Staphylococcus aureus, Klebsiella pneumoniae, Pseudomonas aeruginosa, and Escherichia coli compared to parent chitosan and chitin [243]. Chitosan-based controlled release and targeted formulations developed so far are compiled in Table 2.

\section{Alginate}

It is an extensively studied linear polysaccharide derived from brown seaweed (Macrocystis pyrifera, Laminaria hyperborean) and from some certain bacteria belonging to the family Pseudomonas and Azotobacter. Similar to chitosan, aginate also form a thick gel at low $\mathrm{pH}$, which served as a barrier for controlled release of therapeutics. Additionally, alginate also form thick gel with certain polyvalent cations $\left(\mathrm{Ca}^{2+}\right.$ and $\left.\mathrm{Na}^{+}\right)$due to crosslinking of carboxylic groups of polysaccharide structure. Due to the bioadhesion property of alginate, it offers targeted drug delivery applications. So far, this polysaccharide has been explored for variety of formulations including matrix tablet [244], microspheres [245], pellets [246] and nanoparticles for targeted and functionalized delivery [247] (Table 2). The combination of S-nitroso-mercaptosuccinate (a nitric oxide donor) and green tea synthesized silver nanoparticles incorporated into alginate hydrogel showed synergistic antimicrobial activity against Staphylococcus aureus, Escherichia coli and Streptococcus mutants compared to individual compounds [248].

\section{Pectin}

Pectin is a complex polysaccharide present almost one third of the dry cell wall material of most of the plants. These are higher molecular weight $(50,000$ and $150,000 \mathrm{Da})$ polysaccharides consist $\alpha-(1-4)$ linked esterified D-galacturonic moiety. Various physicochemical parameters of pectin like solubility, viscosity and gelling properties depends upon the degree of methyl esterification of D-galacturonic moiety. Depending upon the degree of esterification two types of pectin are commercially available; highmethoxyl pectins (degree of esterification $>50$ ) and low methoxyl pectins (degree of esterification $<50$ ) [249]. Various plant pectins reportedly exhibit applications as controlled release excipients in tablet, hydrogels and pellets. Additionally, plant pectins offer applications in colon targeted drug delivery due to their biodegradation potential by colonic microflora [250]. The pectin polysaccharide from Ulmus pumila L. (PPU) possess potent anti-inflammatory activity. It was observed that the selenized-PPU inhibit lipopolysaccharide (LPS)-stimulated nitric oxide release by targeting the protein expression of inducible nitric oxide synthase in murine macrophage cell line RAW 264.7 [251].

\section{Guar Gum}

It is a high molecular weight linear polysaccharide obtained from the seeds of the plant Cyamopsis tetragonoloba. The polysaccharide consist of linear chain of $(1 \rightarrow 4)$-linked $\beta$-D-mannopyranosyl units with $(1 \rightarrow 6)$ linked $\alpha$-D-galactopyranosyl residues as side chains with the ratio of mannose to galactose units as 2:1. This polysaccharide swells in polar solvent and thus has been widely explored for various pharmaceutical applications. Addition of ionic and non-ionic additives (sodium chloride and glycerin) could change the swelling and erosion property of polysaccharide for offering a variety of applications [14]. This polysaccharide serves as tablet binder sustain release polymer and viscosity enhancers. This polysaccharide has become the primary choice as excipient in colon specific oral product as it remain indigestible in upper GIT and completely degrades by the colonic microflora [252]. GamalEldeen prepared guar gum C-glycosylated derivative (GG) and its 
Table 2

Different polysaccharides explored for the sustained release of pharmaceuticals.

\begin{tabular}{|c|c|c|c|c|}
\hline Polysaccharide & Formulation & Drug & Remark & Ref. \\
\hline \multirow[t]{4}{*}{ Chitosan } & Oral Tablet & Sodium valproate & Extended release behavior of embedded drug upto $24 \mathrm{~h}$ & [260] \\
\hline & Hydrogel & $\begin{array}{l}\text { Caffeine, Ascorbic acid, and 5- } \\
\text { fluorouracil }\end{array}$ & Extended drug release upto $24 \mathrm{~h}$ & [261] \\
\hline & Bioadhesive vaginal tablet & Fluconazole & Delayed release with $\mathrm{T}_{80} 17.4 \mathrm{~h}$ & [262] \\
\hline & Dry powder inhaler & Rifampicin and Rifabutin & $\begin{array}{l}\text { Sustained release at pulmonary region, upto } 12 \mathrm{~h} \text { for rifampicin and up to } 96 \mathrm{~h} \\
\text { for rifabutin }\end{array}$ & [263] \\
\hline \multirow[t]{4}{*}{ Alginate } & Matrix Tablet & Metronidazole & $\begin{array}{l}\text { Effect of particle size of drug, additive used, and } \mathrm{pH} \text { of medium was evaluated } \\
\text { on drug release }\end{array}$ & [244] \\
\hline & Microspheres & Blue dextran & Extended drug release upto $24 \mathrm{~h}$ & [245] \\
\hline & Pellets & Theophylline & Incorporation of Ca salt prolong the drug release & [246] \\
\hline & Nanoparticles & Cisplatin & Folate conjugation provide selectively taken up by HNE- 1 cells and Hep- 2 cells & [247] \\
\hline \multirow[t]{3}{*}{ Pectin } & Colon specific microparticles & Methotrexate & Microparticles were prepared by ion gelation method & [250] \\
\hline & Nanoparticles & Diclofenac sodium & Nanoparticles were able to release the drug for prolonged period of time & [264] \\
\hline & Pectin coated liposome & Vitamin C & Significant improvement in permeation & [265] \\
\hline \multirow[t]{4}{*}{ Guar gum } & Colon Tablet & Metronidazole & More availability of drug at colon & [252] \\
\hline & $\begin{array}{l}\text { Folic acid conjugated } \\
\text { nanoparticles }\end{array}$ & Methotrexate & Enhanced uptake of delivery systems by colorectal cancer cells & [266] \\
\hline & Nanoaggregates & Isoniazid and Rifampicin & Formulations shows enhanced local action due to sustained release & [267] \\
\hline & Hydrogel & Rifampicin & Enhance mucoadhesion thus better efficacy & [268] \\
\hline \multirow[t]{3}{*}{ Starch } & Microspheres & Oregano essential oil & High antioxidant activity values and stability & [257] \\
\hline & Microparticles & Curcumin & Enhance stability against photodegradation and chemical oxidation & [258] \\
\hline & Nanoparticles & $\begin{array}{l}\text { CG-1521 (histone deacetylase } \\
\text { inhibitor) }\end{array}$ & $\begin{array}{l}\text { Decrease release rate of CG-1521 allowing remarkable cytotoxicity against } \\
\text { MCF-7 breast cancer }\end{array}$ & [259] \\
\hline
\end{tabular}

sulphated derivative (SGG) to investigate its anti-cancer and antiinflammatory potency. It was observed that GG inhibits cytochrome P450 1A (a carcinogen activator enzyme) and stimulated the carcinogen-neutralizing enzymes such as glutathione-S-transferases. Furthermore, both GG and SGG were able to exert anti-inflammatory by reducing the release of nitric oxide and tumor necrosis factor-alpha in LPS induced RAW264.7. GG and SGG also inhibited the proliferation of human hepatocellular carcinoma cells (Hep G2), while only SGG was particularly toxic for MCF-7 [253]. Table 2 presents the selected applications of guar gum as pharmaceutical excipients.

\section{Starch}

Starch is a naturally available polysaccharide obtained from plants. Its characteristic properties such as biotolerance and nonimmunogenicity for human use, and easy availability make it a commonly used polymers/pharmaceutical excipient [254,255]. In comparison to other polymers such as gum and cellulose, starch does not need to undergo excessive purification, as they are relatively pure. Structurally, starch has two different glucan chains a. amylose (linear polymer) and b. amylopectin (branched polymer) representing 98-99\% of the dry weight. In the production of capsules and tablets, starch is widely utilized as a lubricant, diluent, binder and disintegrant whereas it is also commonly employed for variety of specialized drug delivery applications, for example delivery of specialized drug and targeting specific parts of human body [256]. The microsphere of oregano essential oil prepared by starch-based material utilizing supercritical fluid technology showed superior antioxidant capacity (in terms of oxygen radical absorbing capacity) and stability. Starch-based drug carrier systems present high efficacy in the oral delivery of insoluble drugs [257]. Luo et al. encapsulated curcumin into starch microparticles and the formulation showed enhanced stability against photodegradation and oxidative modification. Furthermore, the size of curcumin starch microparticles was possible to control accurately from $0.3-2 \mu \mathrm{m}$ by altering the rate of debranching reaction that caused alteration of release characteristic of curcumin. These observations suggested the management of the release site by modifying the crystallinity or size of microparticles [258]. Alp et al., formulated starch nanoparticles for the delivery of epigenetic drugs CG-1521 for breast cancer that inhibits histone deacetylase. The nanoparticles formulation showed decrease release rate of CG-1521 allowing remarkable cytotoxicity against MCF-7 breast cancer cell as compared to free CG-1521 [259].

\section{Polysaccharides as emulsion stabilizers}

The amphiphilic nature of chemically modified polysaccharides causes their adsorption at the interface of oil and aqueous solvents that results in the stabilization of the emulsion [269]. This property of polysaccharides proved highly beneficial for the delivery of lipophilic or non-polar therapeutics at their target site [270]. As such, the native cellulose does not offer emulsion stabilization due to its non-solubility in water. The chemically modified cellulose not only improves its aqueous solubility but also affords the stabilization of the emulsion [271]. The large size of polysaccharides slows down their adsorption process compared to the small sized surface-active agents. Mainly, the polysaccharide-based emulsifiers mainly base on pectins, gum arabic, galactomannans, and cellulose. Cellulose and starch promote the emulsion stabilization only after their chemical modification however; the polysaccharides such as gum arabic and pectins endowed with covalently linked glycoproteins possess intrinsic ability for the stabilization of the emulsion. In addition, the polysaccharides such as xanthan gum, carrageenan, alginates, hyaluronan, chitosan, and alginates that display trivial interfacial activity offer the eulsion stabilization via thickening, gelling, and structuring [272]. The structural relationship between chitin-based nanomaterials to that of cellulose results in a similar amphiphilic behavior for potential applications as stabilizers of oil-in-water Pickering emulsion. Starch microgranules demonstrate similar applications however; the nanocrystals and nanospheres of starch exhibit a limited stabilization of the emulsion [273]. Yan et al. reported the stabilization of Pickering emulsions droplets by nanocrystals of bacterial cellulose for hydrophobic drug delivery of Alfacalcidol. The irreversible adsorption of bacterial cellulose nanocrystals at the oil-water interface of Pickering emulsions prevented the coalescence of the droplets. The emulsion showed Ostwald ripening in the alginate solution. The interfacial assembly of the amphiphilic bacterial cellulose nanocrystals and the hydrogel shells of the alginate beads generated by the external gelation led to the achievement of efficient loading and a controlled release of Alfacalcidol. The release mechanism of Alfacalcidol from the composite beads followed non-Fickian transport. The alginate composite beads demonstrated minimal toxicity that further proved beneficial for drug delivery applications. Koshani et al. presented the lipophilic drug delivery applications via natural emulgel obtained from dialdehyde cellulose crosslinked with chitosan. The delivery of the lipophilic compound $\beta$-carotene occurred using an embedded oil-in-water emulsion. The lipophilic $\beta$-carotene loaded in the 
oil-phase showed $20 \%$ release in stomach after passing safely through the oral cavity. Furthermore, $50 \%$ of $\beta$-carotene released in the intestines after $4 \mathrm{~h}$ in the presence of emulgel thereby indicating its application as oral delivery vehicle [274].

\section{Clinical trials on Polysaccharide based drug delivery systems}

Riedl et al. performed phase I clinical trials on the dextranconjugated doxorubicin on 13 patients at a starting dose of $40 \mathrm{mg} / \mathrm{m}^{2}$ that led to the development of WHO grade IV thrombocytopenia in $2 / 2$ patients. Whereas, the WHO grade IV hepatotoxicity, and WHO grade III cardiotoxicity appeared in patients with preexisting heart ailments. Lowering of the dose to $20 \mathrm{mg} / \mathrm{m}^{2}$ further decreased the existence of thrombocytopenia. However, the hepatotoxicity persisted. Further reducing the dose to $12.5 \mathrm{mg} / \mathrm{m}^{2}$ caused marked reduction in the malignancy fibrous histiocytoma for up to 4 months [275]. Soepenberg et al. performed phase I clinical trials on DE-310, a camptothecin analog, and a carboxymethyldextran polyalcohol carrier, in the patients with advanced solid tumors. The DE-301 drug delivery system reportedly released DX-8951 drug slowly, while maintaining a sustained release. This prolonged the drug exposure at its deliberated tumor site. Some patients showed partial-to-complete remission of metastatic adenocarcinoma at dose $7.5 \mathrm{mg} / \mathrm{m}^{2}$ [276]. Kim et al. conducted phase II clinical trials on holmium 166/ chitosan complex for the effective treatment of hepatocellular carcinoma. The percutaneous administration of the nanosystem caused a complete tumor necrosis in $31 / 40$ patients after 2 months period. However, a long-term follow-up period indicated recurring of tumor in 28 patients. The polysaccharide based drug delivery system proved beneficial for the treatment of small hepatocellular carcinoma by performing local ablative procedure [277]. Pinnix et al. performed single-blind randomized phase III clinical trials on topical hyaluronic acid after adjuvant radiotherapy for breast cancer. The topical hyaluronic based gel did not proved effective for the treatment of grade 2 dermatitis following radiotherapy [278]. Pritchard et al. reported phase II clinical trials on oligosaccharide polymer therapy for modification of mucus barrier of COPD. The binding of the oligosaccharide caused alteration in the surface charge, porosity, and 3-D mucin networks in sputum of patients with cystic fibrosis, and its inhalation in patients caused effective deposition in lungs and altered the viscoelasticity of the cystic fibrosis sputum [279].

\section{Conclusion and future perspectives}

The polysaccharide based drug-delivery vehicles traversed a long journey for the controlled release of pharmaceuticals at the target site with minimized ensuing side effects caused by the customary delivery vectors. The biodegradability and trivial immunogenicity of the polysaccharide-based drug delivery vehicles makes them the material of the future. The controlled release profile offers improved drug pharmacokinetics thereby leading to ameliorated local action, and effectivity. As such, the polysaccharides present the first-in-class drug delivery system 'Novochizol' for the delivery of COVID-19 drugs. The system comprises of biodegradable and biocompatible chitosan nanoparticles that strongly adhere to the lung epithelium and offers a sustained drug-release. Similarly, the recent discovery of helical V-amylose as advanced drug delivery system further validated the precedence of polysaccharides as drug delivery vehicles. The helical morphology of Vamylose offers drug encapsulation in the helix groves while interacting with the functional head groups. This system proved highly advantageous for the delivery of indomethacin, diclofenac, and aspirin with enhanced gastric tolerance. The conjugation of polysaccharides with metal nanoparticles with unique physicochemical profile in the form of optical, electronic, magnetic, and surface properties provide nanoprobes that present a sturdy candidature in bioimaging of the effected site, while delivery the cargo pharmaceutical at the same time. The development of multicompartmental microspheres based on polysaccharides revolutionized bioengineering and multi-drug delivery with high precision. The coaxial electrospun fiber membranes based on polysaccharides transformed the plant grafting techniques and effectively managed the plant tissue injury due to their high mechanical and tensile strength. The biological phenomenon such as wood degradation by brown-rot fungi led to the development of bioinspired, core shell cellulose microparticles for the light-triggered release of anticancer drugs. Furthermore, the stabilization of Pickering emulsions by chemically modified polysaccharides play a significant role in the lipophilic drug delivery applications, and targeted delivery of various pharmaceuticals and bioactive ingredients.

Despite several benefits, the polysaccharide-based formulations suffer limitations such as susceptibility towards microbial contamination, uncontrolled hydration rate, and reduced viscosity during storage. To overcome these limitations, it mandates the modification of natural polysaccharides via cross-linking, grafting, and blending with natural and synthetic polymers to improve their physicochemical profile. Similarly, the limited knowledge about the mechanism of drug release by polysaccharides, and permeation enhancement decelerates the progressive developments in polysaccharide-based drug delivery systems.

\section{Declaration of Competing Interest}

The authors declare that they have no known competing financial interests or personal relationships that could have appeared to influence the work reported in this paper.

\section{References}

[1] Z. Liu, Y. Jiao, Y. Wang, C. Zhou, Z.J. Zhang, Polysaccharides-based nanoparticles as drug delivery systems, Adv. Drug Deliv. Rev. 60 (2008) 1650-1662.

[2] K. Janes, P. Calvo, M.J. Alonso, Polysaccharide colloidal particles as delivery systems for macromolecules, Adv. Drug Deliv. Rev. 47 (2001) 83-97.

[3] A.F. Metaxa, E. Vrontaki, E.K. Efthimiadou, T. Mavromoustakos, Drug delivery systems based on modified polysaccharides: synthesis and characterization, in: T. Mavromoustakos, A.G. Tzakos, S. Durdagi (Eds.), Supramolecules in Drug Discovery and Drug Delivery. Methods in Molecular Biology 2207, Humana, New York, NY, 2021, https://doi.org/10.1007/978-1-0716-0920-0_12.

[4] V. Singh, et al., Polysaccharide-based nanoparticles: nanocarriers for sustained delivery of drugs, in: A. Nayak, M. Hasnain (Eds.), Advanced Biopolymeric Systems for Drug Delivery. Advances in Material Research and Technology, Springer, Cham, 2020, https://doi.org/10.1007/978-3-030-46923-8_7.

[5] Y. Zheng, Q. Xie, H. Wang, Y. Hu, B. Ren, X. Li, Recent advances in plant polysaccharide-mediated nano drug delivery systems, Int. J. Biol. Macromol. 165 (2020) 2668-2683.

[6] Y. Sun, X. Jing, X. Ma, Y. Feng, H. Hu, Versatile types of polysaccharide-based drug delivery systems: from strategic design to cancer therapy, Int. J. Mol. Sci. 21 (2020), 9159.

[7] A.K. Nayak, M.S. Hasnain, A.K. Dhara, D. Pal, Plant polysaccharides in pharmaceutical applications, in: D. Pal, A.K. Nayak (Eds.), Bioactive Natural Products for Pharmaceutical Applications. Advanced Structured Materials 140, Springer, Cham, 2021, https://doi.org/10.1007/978-3-030-54027-2 3.

[8] K. Park, J.-H. Kim, Y.S. Nam, et al., Effect of polymer molecular weight on the tumor targeting characteristics of self-assembled glycol chitosan nanoparticles, J. Control Release 122 (2007) 305-314.

[9] S. Sudhakar, S.V. Chandran, N. Selvamurugan, R.A. Nazeer, Biodistribution and pharmacokinetics of thiolated chitosan nanoparticles for oral delivery of insulin in vivo, Int. J. Biol. Macromol. 150 (2020) 281-288.

[10] A. Makhlof, M. Werle, Y. Tozuka, H.J. Takeuchi, A mucoadhesive nanoparticulate system for the simultaneous delivery of macromolecules and permeation enhancers to the intestinal mucosa, J. Control. Release 149 (2011) 81-88.

[11] A. Rehman, S.M. Jafari, Q. Tong, T. Riaz, E. Assadpour, R.M. Aadil, S. Niazi, I. M. Khan, Q. Shehzad, A. Ali, S. Khan, Drug nanodelivery systems based on natural polysaccharides against different diseases, Adv. Colloid. Interface Sci. 284 (2020), 102251.

[12] S.H. Lee, R. Bajracharya, J.Y. Min, J.-W. Han, B.J. Park, H.-K. Han, Strategic approaches for colon targeted drug delivery: an overview of recent advancements, Pharmaceutics 12 (2020), 68.

[13] M. Naeem, U.A. Awan, F. Subhan, J. Cao, S.P. Hlaing, J. Lee, E. Im, Y. Jung, J.W. Yoo, Advances in colon-targeted nano-drug delivery systems: challenges and solutions, Arch. Pharmacal. Res. 43 (2020) 153-169.

[14] B. Layek, S. Mandal, Natural polysaccharides for controlled delivery of oral therapeutics: a recent update, Carbohyd. Polym. 230 (2020) 115617.

[15] M. Thanou, J. Verhoef, H.J. Junginger, Oral drug absorption enhancement by chitosan and its derivatives, Adv. Drug Deliv. Rev. 52 (2001) 117-126. 
[16] N.G. Schipper, S. Olsson, J.A. Hoogstraate, A.G. de Boer, K.M. Vårum, P. Artursson, Chitosans as absorption enhancers for poorly absorbable drugs 2 : mechanism of absorption enhancement, J. Pharm. Res. 14 (1997) 923-929.

[17] A. Almeida, M. Araujo, R.N. Carballal, F. Andrade, H. Goncalves, R.L. Reis, M. Lucio, S. Schwartz, B. Sarmento, Novel amphiphillic chitosan micelles as carriers for hydrophobic anticancer drugs, Mater. Sci. Eng. C 112 (2020), 110920

[18] R. Shafabakhsh, B. Yousefi, Z. Asemi, B. Nikfar, M.A. Mansournia, J. Hallajzadeh, Chitosan: a compound for drug delivery system in gastric cancer-a review, Carbohyd. Polym. 242 (2020), 116403.

[19] S. Peers, A. Montembault, C. Ladaviere, Chitosan hydrogels for sustained drug delivery, J. Control. Release 326 (2020) 150-163.

[20] Z.A. Raza, S. Khalil, A. Ayub, I.M. Banat, Recent developments in chitosan encapsulation of various active ingredients for multifunctional applications, Carbohyd. Res. 492 (2020), 108004.

[21] V.M. Platt, F.C. Szoka Jr., Anticancer therapeutics: targeting macromolecules and nanocarriers to hyaluronan or CD44, a hyaluronan receptor, Mol. Pharm. 5 (2008) 474-486.

[22] Y. Kaneo, T. Tanaka, T. Nakano, Y. Yamaguchi, Evidence for receptor-mediated hepatic uptake of pullulan in rats, J. Control. Release 70 (2001) 365-373.

[23] R. Liu, R. Zuo, G.A. Hudalla, Harnessing molecular recognition for localized drug delivery, Adv. Drug Deliv. Rev. 170 (2021) 238-260.

[24] A. Bianchera, R. Bettini, Polysaccharide nanoparticles for oral controlled drug delivery: the role of drug-polymer and interpolymer interactions, Expert Opin. Drug Deliv. 17 (2020) 1345-1359.

[25] X. Chen, W. Han, G. Wang, X. Zhao, Application prospect of polysaccharides in the development of anti-novel coronavirus drugs and vaccines, Int. J. Biol. Macromol. 164 (2020) 331-343.

[26] H.Q. Song, Y. Fan, Y. Hu, G. Cheng, F.-J. Xu, Polysaccharide-peptide conjugates: a versatile material platform for biomedical applications, Adv. Funct. Mater. 31 (2021), 2005978.

[27] S. Naskar, K. Kuotsu, S. Sharma, Chitosan-based nanoparticles as drug delivery systems: a review on two decades of research, J. Drug Target. 27 (2019) 379-393.

[28] D. Wu, L. Zhu, Y. Li, X. Zhang, S. Xu, G. Yang, T. Delair, Chitosan-based colloida polyelectrolyte complexes for drug delivery: a review, Carbohyd. Polym. 238 (2020), 116126.

[29] S. Alban, A. Schauerte, G. Franz, Anticoagulant sulfated polysaccharides: part I. Synthesis and structure-activity relationships of new pullulan sulfates, Carbohyd. Polym. 47 (2002) 267-276.

[30] V.M. Leitner, G.F. Walker, A. Bernkop-Schnürch, Thiolated polymers: evidence for the formation of disulphide bonds with mucus glycoproteins, Eur. J. Pharm. Biopharm. 56 (2003) 207-214.

[31] R.H. Marchessault, F. Ravenelle, X.X. Zhu, Polysaccharides for drug delivery and pharmaceutical applications, in: ACS Symposium Series, 2006.

[32] A.K. Sharma, P. Prasher, A.A. Aljabali, V. Mishra, H. Gandhi, S. Kumar, S. Mutalik, D.K. Chellappan, M.M. Tambuwala, K. Dua, D.N. Kapoor, Emerging era of "somes": polymersomes as versatile drug delivery carrier for cancer diagnostics and therapy, Drug Deliv. Transl. Res. 10 (2020) 1171-1190.

[33] J.-H. Kim, Y.-S. Kim, S. Kim, et al., Hydrophobically modified glycol chitosan nanoparticles as carriers for paclitaxel, J. Control. Release 111 (2006) 228-234.

[34] Z. Negahban, S.A. Shojaosadati, S. Hamedi, A novel self-assembled micelles based on stearic acid modified schizophyllan for efficient delivery of paclitaxel, Colloid Surf. B 199 (2021), 111524.

[35] X. Du, S. Yin, L. Xu, J. Ma, H. Yu, G. Wang, J. Li, Polylysine and cysteine functionalized chitosan nanoparticle as an efficient platform for oral delivery of paclitaxel, Carbohyd. Polym. 229 (2020) 115484.

[36] N. Feng, H. Wu, Y. Xie, Q. Wu, A novel drug delivery system obtained from hydrophobic modified amphiphilic polymers by Maillard reaction, Int. J. Biol. Macromol. 157 (2020) 146-150.

[37] M. Zembala, Electrokinetics of heterogeneous interfaces, Adv. Colloid Interface Sci. 112 (2004) 59-92.

[38] A.A. Kamel, C.M. Ma, M.S. El-Aasser, F.J. Micale, S.A. Vanderhoff, Concerning the origin of charge at the polystyrene particle/water interface, J. Disp. Sci. Technol. 2 (1981) 315-330.

[39] M. Gericke, P. Schulze, T. Heinze, Nanoparticles based on hydrophobic polysaccharide derivatives - formation principles, characterization techniques, and biomedical applications, Macromol. Biosci. 20 (2020), 1900415.

[40] S. Bhattacharjee, DLS and zeta potential-what they are and what they are not? J. Control. Release 235 (2016) 337-351.

[41] R.N. Wijesena, N.D. Tissera, V.W.S.G. Rathnayaka, R.M. Silva, K.M.N. Silva, Colloidal stability of chitin nanofibers in aqueous systems: effect of $\mathrm{pH}$, ionic strength, temperature and concentration, Carbohyd. Polym. 235 (2020), 116024

[42] F. Gambinossi, S.E. Mylon, J.K. Ferri, Aggregation kinetics and colloidal stability of functionalized nanoparticles, Adv. Colloid Interface Sci. 222 (2015) 332-349.

[43] P. Vera, V. Gallardo, J. Salcedo, M.A. Ruiz, A.V. Delgado, Electrokinetics and stability of a cellulose acetate phthalate latex, J. Appl. Polymer Sci. 65 (1997) 2721-2726.

[44] G. Midekessa, K. Godakumara, J. Ord, J. Viil, F. Lattekivi, K. Dissanayake, S. Kopanchuk, A. Rinken, A. Andronowska, S. Bhattacharjee, T. Rinken, A. Fazeli, Zeta potential of extracellular vesicles: towards understanding the attributes that determine colloidal stability, ACS Omega 27 (2020) 16701-16710.

[45] X.-Y. Zhang, Q.-S. Wang, Z.-X. Wu, D.-P. Tao, An experimental study on size distribution and zeta potential of bulk cavitation nanobubbles, Int. J. Minera Metal. Mater. 27 (2020) 152-161.

[46] B.-L. Vinh, N.M.N. Le, I. Nazir, B. Matuszczak, A.B. Schnurch, Chitosan based micelle with zeta potential changing property for effective mucosal drug delivery, Int. J. Biol. Macromol. 133 (2019) 647-655.
[47] J. Jhaveri, Z. Raichura, T. Khan, M. Momin, A. Omri, Chitosan nanoparticlesinsights into properties, functionalization and applications in drug delivery and theranostics, Molecules 26 (2021), 272.

[48] G. Han, S. Liu, Z. Pan, Y. Lin, S. Ding, L. Li, B. Luo, Y. Jiao, C. Zhou, Sulfonated chitosan and phosphorylated chitosan coated polylactide membrane by polydopamine-assisting for the growth and osteogenic differentiation of MC3T3E1s, Carbohyd. Polym. 229 (2020), 115517.

[49] A.J. Bernkop-Schnürch, Strategies to overcome the polycation dilemma in drug delivery, Adv. Drug Deliv. Rev. 136 (2018) 62-72.

[50] L. Wu, W. Shan, Z. Zhang, Y.J. Huang, Engineering nanomaterials to overcome the mucosal barrier by modulating surface properties, Adv. Drug Deliv. Rev. 124 (2018) 150-163.

[51] A. George, P.A. Shah, P.S. Srivastava, Natural biodegradable polymers based nano-formulations for drug delivery: a review, Int. J. Pharm. 561 (2019) 244-264.

[52] A. Gagliardi, E. Giuliano, E. Venkateshwararao, M. Fresta, S. Bulotta, V. Awasthi, D. Cosco, Biodegradable polymeric nanoparticles for drug delivery to solid tumors, Front. Pharmacol. 12 (2021), 601626.

[53] M.S. Hasnain, et al., Biopolymers for drug delivery, in: A. Nayak, M. Hasnain (Eds.), Advanced Biopolymeric Systems for Drug Delivery. Advances in Material Research and Technology, Springer, Cham, 2020, https://doi.org/10.1007/9783-030-46923-8_1.

[54] V. Gopinath, S. Saravanan, A.R. Maleki, M. Ramesh, J. Vadivelu, A review of natural polysaccharides for drug delivery applications: special focus on cellulose, starch and glycogen, Biomed. Pharmacother. 107 (2018) 96-108.

[55] T.G. Barclay, C.M. Day, N. Petrovsky, S. Garg, Review of polysaccharide particlebased functional drug delivery, Carbohyd. Polym. 221 (2019) 94-112.

[56] F. Abedini, M. Ebrahimi, A.H. Roozbehani, A.J. Domb, H. Hosseinkhani, Overview on natural hydrophilic polysaccharide polymers in drug delivery, Polymers Adv. Technol. 29 (2018) 2564-2573.

[57] Y. Yu, Y. Zhu TT-Ergas, G. Fittolani, V. Bardoni, A. Singhal, R.J. Fair, A. Grafmuller, P.H. Seeberger, M. Delbianco, Sysematic hydrogen-bond manipulations to establish polysaccharide structure-property relationship, Angew. Chem. 58 (2019) 13127-13132.

[58] P.-H. Elchinger, P.-A. Faugeras, B. Boens, F. Brouillette, D. Montplaisir, R. Zerrouki, R. Lucas, Polysaccharides: the 'click' chemistry impact, Polymers 3 (2011) 1607-1651.

[59] G. Machell, G.N. Richards, The alkaline degradation of polysaccharides. Part II. The alkali-stable residue from the action of sodium hydroxide on cellulose, J. Chem. Soc. (1957) 4500-4506.

[60] R.L. Whistler, J. BeMiller, Alkaline Degradation of Polysaccharides. Advances in Carbohydrate Chemistry 13, Elsevier, 1958, pp. 289-329.

[61] Y. Ding, Y. Yan, Y. Peng, D. Chen, J. Mi, L. Lu, Q. Luo, X. Li, X. Zeng, Y. Cao, In vitro digestion under simulated saliva, gastric and small intestinal conditions and fermentation by human gut microbiota of polysaccharides from the fruits of Lycium barbarum, Int. J. Biol. Macromol. 125 (2019) 751-760.

[62] T. Di, G. Chen, Y. Sun, S. Ou, X. Zeng, H. Ye, In vitro digestion by saliva, simulated gastric and small intestinal juices and fermentation by human fecal microbiota of sulfated polysaccharides from Gracilaria rubra, J. Funct. Food. 40 (2018) 18-27.

[63] X. Li, R. Guo, X. Wu, X. Liu, L. Ai, Y. Sheng, Z. Song, Y. Wu, Dynamic digestion of tamarind seed polysaccharide: indigestibility in gastrointestinal simulations and gut microbiota changes in vitro, Carbohyd. Polym. 239 (2020), 116194.

[64] J.M. Krochta, J.S. Hudson, S.J. Tillin, Kinetics of Alkaline Thermochemica Degradation of Polysaccharides to Organic Acids, ACS Publications, 1988.

[65] N.G. Kotla, S. Rana, G. Sivaraman, O. Sunnapu, P.K. Vemula, A. Pandit, Y. Rochev, Bioresponsive drug delivery systems in intestinal inflammation: stateof-the-art and future perspectives, Adv. Drug Deliv. Rev. 146 (2019) 248-266.

[66] P. Prasher, R. Fatima, M. Sharma, Therapeutic delivery with V-amylose, Drug Dev. Res. (2021), https://doi.org/10.1002/ddr.21804.

[67] B. Stone, B. Svensson, M. Collins, R. Rastall, Polysaccharide degradation, in: B O. Fraser-Reid, K. Tatsuta, J. Thiem (Eds.), Glycoscience, Springer, Berlin, Heidelberg, 2008, https://doi.org/10.1007/978-3-540-30429-6_60.

[68] S. Rodrigues, L. Cardoso, A.M.R. Da Costa, A. Grenha, Biocompatibility and stability of polysaccharide polyelectrolyte complexes aimed at respiratory delivery, Materials 8 (2015) 5647-5670.

[69] X. Lu, N. Li, X. Qiao, Z. Qiu, P. Liu, Effects of thermal treatment on polysaccharide degradation during black garlic processing, LWT 95 (2018) 223-229.

[70] B.O. Fraser-Reid, K. Tatsuta, J. Thiem, Glycoscience-Chemistry and Chemical Biology I-III, Springer, 2008.

[71] J. Fu, J. Ji, W. Yuan, J.J.B. Shen, Construction of anti-adhesive and antibacterial multilayer films via layer-by-layer assembly of heparin and chitosan, Biomaterial 26 (2005) 6684-6692.

[72] M.G. Carneiro-da-Cunha, M.A. Cerqueira, B.W. Souza, S. Carvalho, M.A. Quintas, J.A. Teixeira, A.A. Vicente, Physical and thermal properties of a chitosan/alginate nanolayered PET film, Carbohyd. Polym. 82 (2010) 153-159.

[73] B.B.S. Cerqueira, A. Lasham, A.N. Shelling, R.J.M.S. Al-Kassas, Development of biodegradable PLGA nanoparticles surface engineered with hyaluronic acid for targeted delivery of paclitaxel to triple negative breast cancer cells, Mater. Sci. Eng. C Mater. Biol. Appl. 76 (2017) 593-600.

[74] V. Milkova, F.M. Goycoolea, Encapsulation of caffeine in polysaccharide oil-core nanocapsules, Colloid Polym. Sci. 298 (2020) 1035-1041.

[75] F. Shi, X. Tian, D.J. McClements, Y. Chang, J. Shen, C. Xue, Influence of molecular weight of an anionic marine polysaccharide (sulfated fucan) on the stability and digestibility of multilayer emulsions: establishment of structure-function relationships, Food Hydrocolloid. 113 (2021), 106418. 
[76] S. Iqbal, Z. Xu, H. Huang, X.D. Chen, Structuring of water-in-oil emulsions using controlled aggregation of polysaccharide in aqueous phases, J. Food Eng. 258 (2019) 34-44.

[77] M. Farid-Ul-Haq, M.A. Hussain, M.T. Haseeb, M.U. Ashraf, S.Z. Hussain, T. Tabassum, I. Hussain, M. Sher, S.N.A. Bukhari, M.N. Hassan, A stimuliresponsive, superporous and non-toxic smart hydrogel from seeds of mugwort (Artemisia vulgaris): stimuli responsive swelling/deswelling, intelligent drug delivery and enhanced aceclofenac bioavailability, RSC Adv. 10 (2020) 19832-19843.

[78] M.A. Hussain, A.I. Rana, M.T. Haseeb, G. Muhammad, L. Kiran, Citric acid cross linked glucuronoxylans: a pH-sensitive polysaccharide material for responsive swelling-deswelling vs various biomimetic stimuli and zero-order drug release, J. Drug Deliv. Sci. Technol. 55 (2020), 101470.

[79] C. Wilson, N. Washington, J. Greaves, F. Kamali, J. Rees, A. Sempik, J. F. Lampard, Bimodal release of ibuprofen in a sustained-release formulation: a scintigraphic and pharmacokinetic open study in healthy volunteers under different conditions of food intake, Int. J. Pharmaceutic. 50 (1989) 155-161.

[80] M.V. Gonzalez, I. Willner, Stimuli-responsive biomolecule-based hydrogels and their applications, Angew. Chem. 59 (2020) 15342-15377.

[81] H.-G. Fu, Y. Chen, Q. Yu, Y. Liu, Polysaccharide-based nanoparticles for two-step responsive release of antitumor drug, ACS Med. Chem. Lett. 11 (2020) 1191-1195.

[82] I. Gholamali, Stimuli-responsive polysaccahride hydrogels for biomedical applciations: a review, Regener. Eng. Transl. Med. 7 (2021) 91-114.

[83] S. Graham, P.F. Marina, A. Blencowe, Thermoresponsive polysaccharides and their thermoreversible physical hydrogel networks, Carbohyd. Polym. 207 (2019) 143-159.

[84] B. Sasa, P. Odon, S. Stane, K. Julijana, Analysis of surface properties of cellulose ethers and drug release from their matrix tablets, Eur. J. Pharm. Sci. 27 (2006) 375-383.

[85] N. Raghav, N. Mor, R.D. Gupta, R. Kaur, M.R. Sharma, P. Arya, Some cetyltrimethylammonium bromide modified polysaccharide supports as sustained release systems for curcumin, Int. J. Biol. Macromol. 154 (2020) 361-370.

[86] R. Zhang, M. Tang, A. Bowyer, R. Eisenthal, J.J.B. Hubble, A novel pH-and ionicstrength-sensitive carboxy methyl dextran hydrogel, Biomaterial 26 (2005) $4677-4683$.

[87] G. Kowalski, K. Kijowska, M. Witczak, L. Kuterasinski, M. Lukasiewicz, Synthesis and effect of structure on swelling properties of hydrogels based on high methylated pectin and acrylic polymers, Polymer 11 (2019), 114.

[88] Y. Guo, J. Sun, S. Bai, X. Wu, pH-Sensitive performance of dextran-poly (acrylic acid) copolymer and its application in controlled in vitro release of ibuprofen, Int. J. Polym. Mater. Polym. Biomater. 66 (2017) 900-906.

[89] D. Hua, R. Xiong, K. Braeckmans, B. Scheid, C. Huang, F. Sauvage, S.C.D. Smedt, Concentration gradients in material sciences: methods to design and biomedical applications, Adv. Func. Mater. 31 (2021), 2009005.

[90] N. Lin, A. Dufresne, Nanocellulose in biomedicine: current status and future prospect, Eur. Polym. J. 59 (2014) 302-325.

[91] H. Ni, S. Zeng, J. Wu, X. Cheng, T. Luo, W. Wang, W. Zeng, Y. Chen, Cellulose nanowhiskers: preparation, characterization and cytotoxicity evaluation, Biomed. Mater. Eng. 22 (2012) 121-127.

[92] K. Azuma, T. Osaki, S. Ifuku, H. Maeda, M. Morimoto, O. Takashima, T. Tsuka, T. Imagawa, Y. Okamoto, H. Saimoto, S. Minami, Suppressive effects of cellulose nanofibers-made from adlay and seaweed-on colon inflammation in an inflammatory bowel-disease model, Bioactive Carbohyd. Diet. Fibre. 2 (2013) 65-72.

[93] M.A. Dobrovolskaia, S.E. McNeil, Immunological properties of engineered nanomaterials, Nat. Nanotechnol. 2 (2007) 469-478.

[94] M. Brenk, M. Scheler, S. Koch, J. Neumann, O. Takikawa, G. Häcker, T. Bieber, D. von Bubnoff, Tryptophan deprivation induces inhibitory receptors ILT3 and ILT4 on dendritic cells favoring the induction of human CD4+ CD25+ Foxp3+ T regulatory cells, J. Immunol. 183 (2009) 145-154.

[95] J. Đokić, S. Tomić, M. Marković, P. Milosavljević, M. Colić, Mesenchymal stem cells from periapical lesions modulate differentiation and functional properties of monocyte-derived dendritic cells, Eur. J. Immunol. 43 (2013) 1862-1872.

[96] O. Parolini, F. Alviano, I. Bergwerf, D. Boraschi, C. De Bari, P. De Waele, M. Dominici, M. Evangelista, W. Falk, S. Hennerbichler, et al., Toward cell therapy using placenta-derived cells: disease mechanisms, cell biology, preclinical studies, and regulatory aspects at the round table, Stem Cell Dev. 19 (2010) 143-154.

[97] S. Tomić, V. Kokol, D. Mihajlović, A. Mirčić, M. Čolić, Native cellulose nanofibrills induce immune tolerance in vitro by acting on dendritic cells, Sci. Rep. 6 (2016) 31618.

[98] P.J. Eggenhuizen, B.H. Ng, J.D. Ooi, Treg enhancing therapies to treat autoimmune diseases, Int. J. Mol. Sci. 21 (2020), 7015.

[99] E.B. Okeke, J.E. Uzonna, Th epivotal role of regulatory T cells in the regulation of innate immune cells, Front. Immunol. 10 (2019), 680.

[100] N. Gupta, A.K. Jangid, D. Pooja, H. Kulhari, Inulin: a novel and stretchy polysaccharide tool for biomedical and nutritional applications, Int. J. Biol. Macromol. 132 (2019) 852-863.

[101] K. Sampathkumar, S.C.J. Loo, Targeted gastrointestinal delivery of nutraceuticals with polysaccharide-based coatings, Macromol. Biosci. 18 (2018), 1700363.

[102] E.V. Lopez, A.L. Alvarez, J.B. Mendez, F.J.O. Espinar, Cellulose-polysaccharide film-coating of cyclodextrin based pellets for controlled drug release, J. Drug Deliv. Sci. Technol. 42 (2017) 273-283.
[103] S. Gao, G. Tang, D. Hua, R. Xiong, J. Han, S. Jiang, Q. Zhang, C. Huang, Stimuliresponsive bio-based polymeric systems and their applications, J. Mater. Chem. B. 7 (2019) 709-729.

[104] T. Thambi, D.G. You, H.S. Han, V.G. Deepagan, S.M. Jeon, Y.D. Suh, K.Y. Choi, K. Kim, I.C. Kwon, G.-R. Yi, J.Y. Lee, D.S. Lee, J.H. Park, Bioreducible carboxymethyl dextran nanoparticles for tumor-targeted drug delivery, Adv Healthcare Med. 11 (2014) 1829-1838.

[105] M. Swierczewska, H.S. Han, K. Kim, J.H. Park, S. Lee, Polysaccharide-based nanoparticles for theranostic nanomedicine, Adv. Drug Deliv. Rev. 99 (2016) $70-84$.

[106] J.M. Shin, S.-H. Kim, T. Thambi, D.G. You, J. Jeon, J.O. Lee, B.Y. Chung, D.-G. Jo, J.H. Park, A hyaluronic acid-methotrexate conjugate for targeted therapy of rheumatoid arthritis, Chem. Commun. 50 (2014) 7632-7635.

[107] H. Jung, K.M. Park, J.-A. Yang, E.J. Oh, D.-W. Lee, K. Park, S.H. Ryu, S.K. Hahn, K. Kim, Theranostic systems assembled in situ on demand by host-guest chemistry, Biomaterial 32 (2011) 7687-7694.

[108] Q. Qu, J. Zhang, X. Chen, H. Ravanbakhsh, G. Tang, R. Xiong, B.B. Manshian, S. J. Soenen, F. Sauvage, K. Braeckmans, S.C.D. Smedt, C. Huang, Triggered release from cellulose microparticles inspired by wood degradation by fungi, ACS Sustain. Chem. Eng. 9 (2021) 387-397.

[109] G. Tang, R. Xiong, D. Lv, R.X. Xu, K. Braeckmans, C. Huang, S.C.D. Smedt, Gasshearing fabrication of multicompartmental-microspheres: a one-step and oil-free approach, Adv. Sci. 6 (2019), 1802342.

[110] Z. Guo, G. Tang, Y. Zhou, L. Shuwu, H. Hou, Z. Chen, J. Chen, C. Hu, F. Wang, S.C. D. Smedt, R. Xiong, C. Huang, Fabrication of sustained-release CA-PU coaxial electrospun fiber membranes for plant grafting application, Carbohyd. Polym. 169 (2017) 198-205.

[111] S. Zhao, X. Yu, Y. Qian, W. Chen, J. Shen, Multifunctional magnetic iron oxide nanoparticles: an advanced platform for cancer theranostics, Theranostics 10 (2020) 6278-6309.

[112] H.-W. Cheng, H.-Y. Tsao, C.-S. Chiang, S.-Y. Chen, Advances in nanoparticlemediated cancer immune-theranostics, Adv. Healthcare Mater. 10 (2021), 2001451.

[113] R.G. Thomas, M. Muthiah, M.J. Moon, I.-K. Park, Y.Y. Jeong, SPION loaded poly (L-lysine)/hyaluronic acid micelles as MR contrast agent and gene delivery vehicle for cancer theranostics, Macromol. Res. 25 (2017) 446-451.

[114] M.H. El-Dakdouki, D.C. Zhu, K. El-Boubbou, M. Kamat, J. Chen, W. Li, X. Huang, Development of multifunctional hyaluronan-coated nanoparticles for imaging and drug delivery to cancer cells, Biomacromolecules 13 (2017) 1144-1151.

[115] R. Choi, J. Yang, J. Choi, E.-K. Lim, E. Kim, J.-S. Suh, Y.-M. Huh, S. Haam, Thiolated dextran-coated gold nanorods for photothermal ablation of inflammatory macrophages, Langmuir 26 (2010) 17520-17527.

[116] C. Yue, P. Liu, M. Zheng, P. Zhao, Y. Wang, Y. Ma, L. Cai, IR-780 dye loaded tumor targeting theranostic nanoparticles for NIR imaging and photothermal therapy, Biomater. 34 (2013) 6853-6861.

[117] H.Y. Yoon, S. Son, S.J. Lee, D.G. You, J.Y. Yhee, J.H. Park, M. Swierczewska, S. Lee, I.C. Kwon, S.H. Kim, K. Kim, M.G. Pomper, Glycol chitosan nanoparticles as specialized cancer therapeutic vehicles: Sequential delivery of doxorubicin and Bcl-2 siRNA, Sci. Rep. 4 (2014) 6878.

[118] G.G. D’Ayala, M. Malinconico, P. Laurienzo, Marine derived polysaccharides for biomedical applications: chemical modification approaches, Molecules 13 (2008) 2069-2106.

[119] J.-S. Yang, Y.-J. Xie, W. He, Research progress on chemical modificaition of alginate. A review, Carbohyd. Polym. 84 (2011) 33-39.

[120] M.A. Otache, R.U. Duru, O. Achugasim, O.J. Abayeh, Advances in the modification of starch via esterification for enhanced properties, J. Polym. Environ. 29 (2021) 1365-1379.

[121] C.E. Schante, G. Zuber, C. Herlin, T.F. Vandamme, Chemical modifications of hyaluronic acid for the synthesis of derivatives for a broad range of biomedical applications, Carbohyd. Polym. 85 (2011) 469-489.

[122] A.S. Volokhova, K.J. Edgar, J.B. Matson, Polysaccharide-containing block copolymers: synthesis and applications, Mater. Chem. Front. 4 (2020) 99-112.

[123] A. Synytsya, P. Pouckova, M. Zadinova, Y. Troshchynska, J. Stetina, A. Synytsya, I. Salon, V. Kral, Hydrogels based on low-methoxyl amidated citrus pectin and flaxseed gum formulated with tripeptide glycyl-1-histidyl-1-lysine improve the healing of experimental cutting wounds in rats, Int. J. Biol. Macromol. 165 (2020) 3156-3168.

[124] A.J. Kerchove, M. Elimelech, Formation of polysaccharide gel layers in the presence of $\mathrm{Ca} 2+$ and $\mathrm{K}+$ Ions: measurements and mechanisms, Biomacromolecules 8 (2007) 113-121.

[125] A. Chowhan, T.K. Giri, Polysaccharide as renewable responsive biopolymer for in situ gel in the delivery of drug through ocular route, Int. J. Biol. Macromol. 150 (2020) 559-572.

[126] H. Zhong, X. Gao, C. Cheng, C. Liu, Q. Wang, X. Han, The structural characteristics of seaweed polysaccharides and their applications in gel drug delivery systems, Mar. Drug 18 (2020), 658.

[127] B. Singh, A. Kumar, Graft and crosslinked polymerization of polysaccahride gum to form hydrogel wound dressings for drug delivery applications, Carbohyd. Res. 489 (2020), 107949.

[128] N. Zhang, H. Chen, L. Ma, Y. Zhang, Physical modifications of polysaccharide from Inonotus obliquus and the antioxidant properties, Int. J. Biol. Macromol. 54 (2013) 209-215.

[129] Y. Zhuang, Y. Kong, K. Han, H. Hao, B. Shi, A physically cross-linked self-healable double-network polymer hydrogel as a framework for nanomaterial, New J. Chem. 41 (2017) 15127-15135. 
[130] T. Sasaki, Influence of anionic, neutral, and cationic polysaccharides on the in vitro digestibility of raw and gelatinized potato starch, J. Sci. Food Agric. 100 (2020) 2435-2442

[131] M. Farshbaf, S. Davaran, A. Zarebkohan, N. Annabi, A. Akbarzadeh, R. Salehi, Significant role of cationic polymers in drug delivery systems, Artif. Cells Nanomed. Biotechnol. 46 (2018) 1872-1891.

[132] H.H. Tonnesen, J. Karlsen, Alginate in drug delivery systems, Drug Dev. Indus. Pharm. 28 (2002) 621-630.

[133] J. Li, C. Cai, J. Li, T. Sun, L. Wang, H. Wu, G. Yu, Chitosan-based nanomaterials for drug delivery, Molecules 23 (2018), 2661.

[134] L. Szabo, S.G. Lemaire, C. Wandrey, Strategies to functionalize the anionic biopolymer Na-alginate without restricting its polyelectrolyte properties, Polymers 12 (2020), 919.

[135] E.M.P. Quito, R.R. Caro, M.D. Veiga, Carrageenan: drug delivery systems and other biomedical applications, Mar. Drug 18 (2020), 583

[136] J. Guan, L. Li, S. Mao, Applications of Carrageenan in Advanced Drug Delivery. Seaweed Polysaccharides, Elsevier, 2017.

[137] J.L. Jiang, W.-Z. Zhang, W.-X. Ni, J.-W. Shao, Insight on structure-property relationships of carrageenan from marine red algal: a review, Carbohyd. Polym. 257 (2021), 117642.

[138] Y. Luo, Q. Wang, Recent development of chitosan-based polyelectrolyte complexes with natural polysaccharides for drug delivery, Int. J. Biol. Macromol. 64 (2014) 353-367.

[139] A. Drogoz, L. David, C. Rochas, A. Domard, T. Delair, Polyelectrolyte complexes from polysaccharides: formation and stoichiometry monitoring, Langmuir 23 (2007) 10950-10958.

[140] S. Boddohi, N. Moore, P.A. Johnson, M.J. Kipper, Polysaccharide-based polyelectrolyte complex nanoparticles from Chitosan, Heparin, and Hyaluronan, Biomacromolecules 10 (2009) 1402-1409.

[141] Y. Wu, A. Rashidpour, M.P. Almajano, I. Meton, Chitosan-based drug delivery: applications in fish biotechnology, Polymers 12 (2020), 1177.

[142] J. Potas, E. Szymanska, K. Winnicka, Challenges in developing of chitosan-based polyelectrolyte complexes as a platform for mucosal and skin drug delivery, Eur Polym. J. 140 (2020), 110020.

[143] A. Aguilera-Garrido, T.C. Santaella, Y. Yang, F.G. Gonzalez, M.J.G. Ruiz, J.A. M. Bolivar, J.A.H. Terriza, M.A.C. Vilchez, J.M. Valderrama, Aplications of serum albumins in delivery systems: differences in interfacial behavior and interacting abilities with polysaccharides, Adv. Colloid. Interface Sci. 290 (2021), 102365.

[144] T.E. Kleinman, A.J. Domb, J. Golenser, Polysaccharide scaffolds prepared by crosslinking of polysaccharides with chitosan proteins for cell growth, J. Bioactive Compatible Polym. 18 (2003) 323-338.

[145] N. Reddy, R. Reddy, Q. Jiang, Crosslinking biopolymers for biomedical applications, Trend. Biotechnol. 33 (2015) 362-369.

[146] J.N. Putro, S. Ismadji, C. Gunarto, F.E. Soetaredjo, Y.H. Ju, Effect of natural and synthetic surfactants on polysaccharide nanoparticles: hydrophobic drug loading, release, and cytotoxic studies, Colloid Surf. A 578 (2019), 123618.

[147] Z. Petronijevic, B. Maluckov, A. Smelcerovic, Crosslinking of polysaccharides with activated dimethylsulfoxide, Tetrahed. Lett. 54 (2013) 3210-3214.

[148] P.F. Cui, W.-R. Zhuang, X. Hu, L. Xing, R.-Y. Yu, J.-B. Qiao, Y.-J. He, F. Li, D. Ling, H.-L. Jiang, A new strategy for hydrophobic drug delivery using a hydrophilic polymer equipped with stacking units, Chem. Commun. 54 (2018) 8218-8221.

[149] C.A. Lorenzo, B.B. Fernandez, A.M. Puga, A. Concheiro, Crosslinked ionic polysaccharides for stimuli-sensitive drug delivery, Adv. Drug. Dev. Rev. 65 (2013) 1148-1171.

[150] Y. Wu, X. Zhang, H. Li, P. Deng, H. Li, T. He, J. Rong, J. Zhao, Z. Liu, A core/ shell stabilized polysaccharide-based nanoparticle with intracellular environmentsensitive drug delivery for breast cancer therapy, J. Mater. Chem. B. 6 (2018) 6646-6659.

[151] Y. Yu, T.T. Ergas, Y. Zhu, G. Fittolani, V. Bordoni, A. Singhal, R.J. Fair, A. Grafmuller, P.H. Seeberger, M. Delbianco, Systematic hydrogen-bond manipulations to establish polysaccharide structure-property correlations, Angew. Chem. 58 (2019) 13127-13132.

[152] F. Zhu, J. Rodriguez, T. Yang, I. Kevlishvili, E. Miller, D. Yi, S. Neill, M.J. Rourke, P. Liu, M.A. Walczak, Glycosyl cross-coupling of anomeric nucleophiles: scope, mechanism, and applications in the synthesis of Aryl C-glycosides, J. Am. Chem. Soc. 139 (2017) 17908-17922.

[153] P.O. Adero, H. Amarasekara, P. Wen, L. Bohe, D. Crich, The experimental evidence in support of glycosylation mechanisms at the SN1-SN2 interface, Chem. Rev. 118 (2018) 8242-8284.

[154] T. Hansen, L. Lebedel, et al., Defining the SN1 Side of glycosylation reactions: stereoselectivity of glycopyranosyl cations, ACS Cent. Sci. 5 (2019) 781-788.

[155] J. Domagalska, K. Pyta, P. Przybylski, Conversion of leucomycin-A3 antibiotic into novel triazole analogues via regio- and diastereoselective SN1' substitution with allylic rearrangement and 1,3-dipolar cycloaddition of CuAAC type, Tet. Lett. 57 (2016) 1661-1666.

[156] J.A.C. Romero, S.A. Tobbacco, K.A. Woerpel, Stereochemical reversal of nucleophilic substitution reactions depending upon substituent: reactions of heteroatom-substituted six-membered-ring oxocarbenium ions through pseudoaxial conformers, J. Am. Chem. Soc. 122 (2000) 168-169.

[157] E.C. Rodriguez, L.A. Marcaurelle, C.R. Bertozzi, Aminooxy-, hydrazide-, and thiosemicarbazide-functionalized saccharides: versatile reagents for glycoconjugate synthesis, J. Org. Chem. 63 (1998) 7134-7135.

[158] K.C.K. Swamy, N.N.B. Kumar, E. Balaraman, K.V.P.P. Kumar, Mitsunobu and related reactions: advances and applications, Chem. Rev. 109 (2009) 2551-2651.

[159] S. Fletcher, The Mitsunobu reaction in the 21st century, Org. Chem. Front. 2 (2015) 739-752.
[160] P.-H. Ehlinger, P.-A. Faugeras, B. Boens, F. Brouillette, D. Montplaisir, R. Zerrouki, R. Lucas, Polysaccharides: the "click" chemistry impact, Polymers 3 (2011) 1607-1651.

[161] T. Tanaka, H. Nagai, M. Naguchi, A. Kobayashi, S.-I. Shoda, One-step conversion of unprotected sugars to $\beta$-glycosyl azides using 2-chloroimidazolinium salt in aqueous solution, Chem. Commun. 23 (2009) 3378-3379.

[162] P. Prasher, M. Sharma, Tailored therapeutics based on 1,2,3-1H-triazoles: a mini review, MedChemComm 10 (2019) 1302-1328.

[163] A. Devadoss, C.E.D. Chidsey, Azide-modified graphitic surfaces for covalent attachment of alkyne-terminated molecules by "click" chemistry, J. Am. Chem. Soc. 129 (2007) 5370-5371.

[164] T. Breton, G. Bashiardes, J.-M. Leger, K.B. Kokoh, Selective oxidation of unprotected carbohydrates to aldehyde analogues by using TEMPO salts, Eur. J. Org. Chem. 10 (2007) 1567-1570.

[165] T. Nagase, S. Shinkai, I. Hamachi, Post-photoaffinity labeling modification using aldehyde chemistry to produce a fluorescent lectin toward saccharide-biosensors, Chem. Comm. (2001) 229-230.

[166] P.S. Chang, J.F. Robyt, Oxidation of primary alcohol groups of naturally occurring polysaccharides with 2,2,6,6-tetramethyl-1-piperidine oxoammonium ion, J. Carbohyd. Chem. 15 (1996) 819-830.

[167] T. Bobula, R. Buffa, H. Vagnerova, R. Sulakova, L. Wolfova, L. Kohutova, V. Moravkova, V. Velebny, Derivatives of Sulfated Polysaccharides, Methods of Preparation, Modification and Use Thereof, 2015 (US10414832B2).

[168] V. Ferro, T. Karoli, L. Liu, P. Newton, T.E. Hammond, Sulfated Oligosaccharide Derivatives, 2007 (USRE46955E1).

[169] X. Pang, X. Yang, G. Zhai, Polymer-drug conjugates: recent progress on administration routes, Expert Opin. Drug Deliv. 11 (2014) 1075-1086.

[170] J. Yang, S. Han, H. Zheng, H. Dong, J. Liu, Preparation and application of micro/ nanoparticles based on natural polysaccharides, Carbohyd. Polym. 123 (2015) 53-66.

[171] C. Chen, J.-L. Zhou, X. Han, F. Song, X.-L. Wang, Y.-Z. Wang, A prodrug strategy based on chitosan for efficient intracellular anticancer drug delivery, Nanotechology 25 (2014), 255101.

[172] C.K. Chen, P.K. Huang, W.C. Law, C.H. Chu, N.T. Chen, L.W. Lo, Biodegradable polymers for gene-delivery applications, Int. J. Nanomed. 15 (2020) 2131-2150.

[173] N.N. Siddiqui, A. Aman, A. Silipo, S.A.U. Oader, A. Molinaro, Structural analysis and characterization of dextran produced by wild and mutant strains of Leuconostoc mesenteroides, Carbohyd. Polym. 99 (2014) 331-338.

[174] J. Sadahiro, H. Mori, W. Saburi, M. Okuyama, A. Kimura, Extracellular and cellassociated forms of Gluconobacter oxydans dextran dextrinase change their localization depending on the cell growth, Biochem. Biophys. Res. Commun. 456 (2015) 500-505.

[175] V. Taghipour-Sabzevar, T. Sharifi, M.M. Moghaddam, Polymeric nanoparticles as carrier for targeted and controlled delivery of anticancer agents, Ther. Deliv. 10 (2019) 527-550.

[176] C. Longinotti, The use of hyaluronic acid based dressings to treat burns: a review, Burns Trauma 2 (2014) 162-168.

[177] A. Mero, M. Pasqualin, M. Campisi, D. Renier, G. Pasut, Conjugation of hyaluronan to proteins, Carbohyd. Polym. 92 (2013) 2163-2170.

[178] J. Starigazdova, K. Nesporova, M. Cepa, R. Sinova, D. Smejkalova, G. HuertaAngeles, V. Velebny, In vitro investigation of hyaluronan-based polymeric micelles for drug delivery into the skin: The internalization pathway, Eur. J. Pharm. Sci. 143 (2020), 105168.

[179] D. Smejkalova, K. Nesporova, G. Huerta-Angeles, J. Syrovatka, D. Jirak, A. Galisova, V.J.B. Velebny, Selective in vitro anticancer effect of superparamagnetic iron oxide nanoparticles loaded in hyaluronan polymeric micelles, Biomacromolecules 15 (2014) 4012-4020.

[180] J. Pushpamalar, A.K. Veeramachineni, C. Owh, X.J. Loh, Biodegradable polysaccharides for controlled drug delivery, ChemPlusChem 81 (2016) 504-514.

[181] N. Goodarzi, R. Varshochian, G. Kamalinia, F. Atyabi, R. Dinarvand, A review of polysaccharide cytotoxic drug conjugates for cancer therapy, Carbohyd. Polym. 92 (2013) 1280-1293.

[182] O.P. Varghese, J. Liu, K. Sundaram, J. Hilborn, O.P. Oommen, Chondroitin sulfate derived theranostic nanoparticles for targeted drug delivery, Biomater. Sci. 4 (2016) 1310-1313.

[183] S. Arpicco, P. Milla, B. Stella, F. Dosio, Hyaluronic acid conjugates as vectors for the active targeting of drugs, genes and nanocomposites in cancer treatment, Molecules 19 (2014) 3193-3230.

[184] C.I.C. Crucho, M.T. Barros, Surfactant-free polymeric nanoparticles for biomedical applications, Microsc. Microanal. 21 (2015) 74-75.

[185] X. Shen, J.L. Shamshina, P. Berton, G. Gurau, R.D. Rogers, Hydrogels based on cellulose and chitin: fabrication, properties, and applications, Green Chem. 18 (2016) 53-75.

[186] R. Jayakumar, A. Nair, N.S. Rejinold, S. Maya, S.J.C.P. Nair, Doxorubicin-loaded pH-responsive chitin nanogels for drug delivery to cancer cells, Carbohyd. Polym. 87 (2012) 2352-2356.

[187] N.S. Rejinold, A. Nair, M. Sabitha, K. Chennazhi, H. Tamura, S.V. Nair, R. Jayakumar, Synthesis, characterization and in vitro cytocompatibility studies of chitin nanogels for biomedical applications, Carbohyd. Polym. 87 (2012) 943-949.

[188] B. Sivakumar, R.G. Aswathy, Y. Nagaoka, M. Suzuki, T. Fukuda, Y. Yoshida, T. Maekawa, D.N.J.L. Sakthikumar, Multifunctional carboxymethyl cellulosebased magnetic nanovector as a theragnostic system for folate receptor targeted chemotherapy, imaging, and hyperthermia against cancer, Langmuir 29 (2013) 3453-3466. 
[189] P. Bossi, L. Locati, C. Bergamini, A. Mirabile, R. Granata, M. Imbimbo, C. Resteghini, L. Licitra, Fentanyl pectin nasal spray as treatment for incident predictable breakthrough pain (BTP) in oral mucositis induced by chemoradiotherapy in head and neck cancer, Oral Oncol. 50 (2014) 884-887.

[190] S. Merino, C. Martín, K. Kostarelos, M. Prato, E. Vázquez, Nanocomposite hydrogels: 3D polymer-nanoparticle synergies for on-demand drug delivery, ACS Nano. 9 (2015) 4686-4697.

[191] D. Bruen, C. Delaney, J. Chung, K. Ruberu, G.G. Wallace, D. Diamond, L. Florea, 3D printed sugar-sensing hydrogels, Macromol Rapid Commun. 41 (2020), e1900610.

[192] W.-L. Song, K. Song, L.-Z. Fan, A versatile strategy toward binary threedimensional architectures based on engineering graphene aerogels with porous carbon fabrics for supercapacitors, ACS Appl. Mater. Interface 7 (2015) 4257-4264.

[193] J. Muller, A.C. Jakel, D. Schwarz, L. Aufinger, F.C. Simmel, Programming diffusion and localization of DNA signals in 3D-printed DNA-functionalized hydrogels, Small 16 (2020), 2001815.

[194] S.G. Kelmanovich, R. Parke-Houben, C.W. Frank, Competitive swelling forces and interpolymer complexation in $\mathrm{pH}$ - and temperature-sensitive interpenetrating network hydrogels, Soft Matter. 8 (2012) 8137-8148.

[195] D.G. Lim, E. Kang, S.H. Jeong, pH-dependent nanodiamonds enhance the mechanical properties of 3D-printed hyaluronic acid nanocomposite hydrogels, J. Nanobiotechnol. 18 (2020), 88.

[196] R. Kolakovic, L. Peltonen, A. Laukkanen, J. Hirvonen, T. Laaksonen, Nanofibrillar cellulose films for controlled drug delivery, Eur. J. Pharm. Biopharm. 82 (2012) 308-315.

[197] L. Li, J. Ge, P.X. Ma, B. Guo, Injectable conducting interpenetrating polymer network hydrogels from gelatin-graft-polyaniline and oxidized dextran with enhanced mechanical properties, RSC Adv. 5 (2015) 92490-92498.

[198] T.T. Khong, O.A. Aarstad, G. Skjåk-Bræk, K.I. Draget, K.M. Vårum, Gelling concept combining chitosan and alginate-proof of principle, Biomacromolecules 14 (2013) 2765-2771.

[199] J. Aalaie, E. Vasheghani-Farahani, A. Rahmatpour, M.A. Semsarzadeh, Gelation rheology and water absorption behavior of semi-interpenetrating polymer networks of polyacrylamide and carboxymethyl cellulose, J. Macromol. Sci. B 52 (2013) 604-613.

[200] S. Wijeratne, M.L. Bruening, G.L. Baker, Layer-by-layer assembly of thick, $\mathrm{Cu}^{2+}$ chelating films, Langmuir 29 (2013) 12720-12729.

[201] N.A. Gujarathi, B.R. Rane, J.K. Patel, pH sensitive polyelectrolyte complex of Ocarboxymethyl chitosan and poly (acrylic acid) cross-linked with calcium for sustained delivery of acid susceptible drugs, Int. J. Pharmaceutics 436 (2012) 418-425.

[202] S. Thenapakiam, D.G. Kumar, J. Pushpamalar, M. Saravanan, Aluminium and radiation cross-linked carboxymethyl sago pulp beads for colon targeted delivery Carbohyd. Polym. 94 (2013) 356-363.

[203] S. Kaity, A. Ghosh, Comparative bio-safety and in vivo evaluation of native or modified locust bean gum-PVA IPN microspheres, Int. J. Biol. Macromol. 72 (2015) 883-893.

[204] V.K. Thakur, M.K. Thakur, Recent trends in hydrogels based on psyllium polysaccharide: a review, J. Clean. Product. 82 (2014) 1-15.

[205] S.K. Nitta, K. Numata, Biopolymer-based nanoparticles for drug/gene delivery and tissue engineering, Int. J. Mol. Sci. 14 (2013) 1629-1654.

[206] D.G. Fatouros, D.A. Lamprou, A.J. Urquhart, S.N. Yannopoulos, I.S. Vizirianakis, S. Zhang, S. Koutsopoulos, Lipid-like self-assembling peptide nanovesicles for drug delivery, ACS Appl. Mater. Interface. 6 (2014) 8184-8189.

[207] S.V. Lale, A. Kumar, S. Prasad, A.C. Bharti, V. Koul, Folic acid and trastuzumab functionalized redox responsive polymersomes for intracellular doxorubicin delivery in breast cancer, Biomacromolecules 16 (2015) 1736-1752.

[208] Y. Lu, K. Park, Polymeric micelles and alternative nanonized delivery vehicles for poorly soluble drugs, Int. J. Pharm. 453 (2013) 198-214.

[209] C. Lautenschläger, C. Schmidt, K. Lange, A. Stallmach, Drug delivery strategies for targeted treatment of inflammatory bowel disease, Gastroenterology 53 (2015) 226-234.

[210] M.R. Saboktakin, N.A. Tabar, R.M. Tabatabaie, A. Maharramov, M.A. Ramazanov, Intelligent drug delivery systems based on modified chitosan nanoparticles, Lett. Org. Chem. 9 (2012) 56-70.

[211] D. Yadav, S. Suri, A. Chaudhary, M. Beg, V. Garg, M. Asif, A. Ahmad, Stimuli responsive polymeric nanoparticles in regulated drug delivery for cancer, Polish J. Chem. Technol. 14 (2012) 57-64.

[212] G. Mead, M. Hiley, T. Ng, C. Fihn, K. Hong, M. Groner, W. Miner, D. Drugan, W. Hollingsworth, A.K. Udit, Directed polyvalent display of sulfated ligands on virus nanoparticles elicits heparin-like anticoagulant activity, Bioconjug. Chem. 25 (2014) 1444-1452.

[213] L. Li, K.M. Huh, Y.-K. Lee, S.Y. Kim, Biofunctional self-assembled nanoparticles of folate-PEG-heparin/PBLA copolymers for targeted delivery of doxorubicin, J. Mater. Chem. 21 (2011) 15288-15297.

[214] Z. Fülöp, P. Saokham, T. Loftsson, Sulfobutylether- $\beta$-cyclodextrin/chitosan nanoand microparticles and their physicochemical characteristics, Int. J. Pharm. 472 (2014) 282-287.

[215] Z. Chen, B. Krishnamachary, M.-F. Penet, Z.M. Bhujwalla, Acid-degradable dextran as an image guided siRNA carrier for COX-2 downregulation, Theranostics 8 (2018) 1-12.

[216] Y. Tang, Y. Li, R. Xu, S. Li, H. Hu, C. Xiao, H. Wu, L. Zhu, J. Ming, Z.J.N. Chu, H. Xu, X. Yang, Z. Li, Self-assembly of folic acid dextran conjugates for cancer chemotherapy, Nanoscale 10 (2018) 17265-17274.
[217] X. Zhang, R. Zhang, J. Huang, M. Luo, X. Chen, Y. Kang, J. Wu, Albumin enhances PTX delivery ability of dextran NPs and therapeutic efficacy of PTX for colorectal cancer, J. Mater. Chem. B 7 (2019) 3537-3545.

[218] Q.S. Zhao, L.I. Hu, Z.D. Wang, Z.P. Li, W.A. Wen, J. Liu, Resveratrol-loaded folic acid-grafted dextran stearate submicron particles exhibits enhanced antitumor efficacy in non-small cell lung cancers, Mater. Sci. Eng. C 72 (2017) 185-191.

[219] Y. Fang, H. Wang, H.-J. Dou, X. Fan, X.-C. Fei, L. Wang, S. Cheng, A. Janin, L. Wang, W.-L. Zhao, Doxorubicin-loaded dextran-based nano-carriers for highly efficient inhibition of lymphoma cell growth and synchronous reduction of cardiac toxicity, Int. J. Nanomed. 13 (2018) 5673-5683.

[220] T. Wang, J. Hou, C. Su, L. Zhao, Y. Shi, Hyaluronic acid-coated chitosan nanoparticles induce ROS-mediated tumor cell apoptosis and enhance antitumor efficiency by targeted drug delivery via CD44, J. Nanobiotechnol. 15 (2017), 7.

[221] Z. Yang, N. Sun, R. Cheng, C. Zhao, J. Liu, Z. Tian, Hybrid nanoparticles coated with hyaluronic acid lipoid for targeted co-delivery of paclitaxel and curcumin to synergistically eliminate breast cancer stem cells, J. Mater Chem. B 5 (2017) 6762-6775.

[222] P. Parashar, M. Rathor, M. Dwivedi, S.A. Saraf, Hyaluronic acid decorated naringenin nanoparticles: appraisal of chemopreventive and curative potential for lung cancer, Pharmaceutics 10 (2018), 33.

[223] J. Li, X. Yang, P. Yang, F.J.I. Gao, Hyaluronic acid-conjugated silica nanoparticles for breast cancer therapy, Inorg. Nanometal Chem. 47 (2017) 777-782.

[224] D.R. Vogus, M.A. Evans, A. Pusuluri, A. Barajas, M. Zhang, V. Krishnan, M. Nowak, S. Menegatti, M.E. Helgeson, T.M. Squires, S. Mitragotri, A hyaluronic acid conjugate engineered to synergistically and sequentially deliver gemcitabine and doxorubicin to treat triple negative breast cancer, J. Control Release 267 (2017) 191-202.

[225] X.-L. Guo, X.-X. Kang, Y.-Q. Wang, X.-J. Zhang, C.-J. Li, Y. Liu, L.-B. Du, Codelivery of cisplatin and doxorubicin by covalently conjugating with polyamidoamine dendrimer for enhanced synergistic cancer therapy, Acta Biomater. 84 (2019) 367-377.

[226] S.A. Shahin, R. Wang, S.I. Simargi, A. Contreras, L.P. Echavarria, L. Qu, W. Wen, T. Dellinger, J. Unternaehrer, F.J.N.N. Tamanoi, Hyaluronic acid conjugated nanoparticle delivery of siRNA against TWIST reduces tumor burden and enhances sensitivity to cisplatin in ovarian cancer, Biol. Med. 14 (2018) 1381-1394.

[227] H. Jiang, X. Shi, X. Yu, X. He, Y. An, H. Lu, Hyaluronidase enzyme-responsive targeted nanoparticles for effective delivery of 5-fluorouracil in colon cancer, Pharm. Res. 35 (2018) 73.

[228] M.A. Raja, M. Arif, C. Feng, S. Zeenat, C.-G. Liu, Synthesis and evaluation of pHsensitive, self-assembled chitosan-based nanoparticles as efficient doxorubicin carriers, J. Biomater. Appl. 31 (2017) 1182-1195.

[229] J. Wu, C. Tang, C. Yin, Co-delivery of doxorubicin and interleukin-2 via chitosan based nanoparticles for enhanced antitumor efficacy, Acta Biomater. 47 (2017) 81-90.

[230] B. Cheng, F. Gao, E. Maissy, P. Xu, Repurposing suramin for the treatment of breast cancer lung metastasis with glycol chitosan-based nanoparticles, Acta Biomater. 84 (2019) 378-390.

[231] V. Alinejad, M.H. Somi, B. Baradaran, P. Akbarzadeh, F. Atyabi, H. Kazerooni, H. S. Kafil, L.A. Maleki, H.S. Mansouri, M. Yousefi, Co-delivery of IL17RB siRNA and doxorubicin by chitosan-based nanoparticles for enhanced anticancer efficacy in breast cancer cells, Biomed. Pharmacother. 83 (2016) 229-240.

[232] A. Abruzzo, G. Zuccheri, F. Belluti, S. Provenzano, L. Verardi, F. Bigucci, T. Cerchiara, B. Luppi, N. Calonghi, Chitosan nanoparticles for lipophilic anticancer drug delivery: development, characterization and in vitro studies on HT29 cancer cells, Colloid. Surf. B 145 (2016) 362-372.

[233] C. Zhang, G. Shi, J. Zhang, J. Niu, P. Huang, Z. Wang, Y. Wang, W. Wang, C. Li, D. Kong, Redox-and light-responsive alginate nanoparticles as effective drug carriers for combinational anticancer therapy, Nanoscale 9 (2017) 3304-3314.

[234] M. Mirrahimi, M. Khateri, J. Beik, F.S. Ghoreishi, A.S. Dezfuli, H. Ghaznavi, A. Shakeri-Zadeh, Enhancement of chemoradiation by co-incorporation of gold nanoparticles and cisplatin into alginate hydrogel, J. Biomed. Mater. Res. 107 (2019) 2658-2663.

[235] A.A. Markeb, N.A. El-Maali, D.M. Sayed, A. Osama, M.A.Y. Abdel-Malek, A. H. Zaki, M.E.A. Elwanis, J.J. Driscoll, Synthesis, structural characterization, and preclinical efficacy of a novel paclitaxel-loaded alginate nanoparticle for breast cancer treatment, Int. J. Breast Cancer 2016 (2016), 7549372.

[236] N.P. Katuwavila, A.D.L.C. Perera, S.R. Samarakoon, P. Soysa, V. Karunaratne, G, A.J. Amaratunga, D.N. Karunaratne, Chitosan-alginate nanoparticle system efficiently delivers doxorubicin to MCF-7 cells, J. Nanomater. 2016 (2016), 3178904.

[237] L. Chen, M. Qian, L. Zhang, J. Xia, Y. Bao, J. Wang, L. Guo, Y. Li, Co-delivery of doxorubicin and shRNA of Beclin1 by folate receptor targeted pullulan-based multifunctional nanomicelles for combinational cancer therapy, RSC Adv. 8 (2018) 17710-17722.

[238] L. Huang, B. Chaurasiya, D. Wu, H. Wang, Y. Du, J. Tu, T.J. Webster, C. Sun, Versatile redox-sensitive pullulan nanoparticles for enhanced liver targeting and efficient cancer therapy, Nanomed. Nanotechnol. Biol. Med. 14 (2018) 1005-1017.

[239] L. Gallo, V. Bucalá, M.V. Ramírez-Rigo, Formulation and characterization of polysaccharide microparticles for pulmonary delivery of sodium cromoglycate, AAPS PharmSciTech. 18 (2017) 1634-1645.

[240] C. Tan, J. Xie, X. Zhang, J. Cai, S. Xia, Polysaccharide-based nanoparticles by chitosan and gum arabic polyelectrolyte complexation as carriers for curcumin, Food Hydrocolloid. 57 (2016) 236-245. 
[241] T. Miao, J. Wang, Y. Zeng, G. Liu, X. Chen, Polysaccharide-based controlled release systems for therapeutics delivery and tissue engineering: from bench to bedside, Adv. Sci. 5 (2018) 1700513.

[242] Y. Cao, Y.F. Tan, Y.S. Wong, M.W.J. Liew, S. Venkatraman, Recent advances in chitosan-based carriers for gene delivery, Mar. Drug 17 (2019) 381.

[243] K. Divya, S. Vijayan, T.K. George, et al., Antimicrobial properties of chitosan nanoparticles: mode of action and factors affecting activity, Fibers Polym. 18 (2017) 221-230.

[244] P. Sriamornsak, N. Thirawong, K. Korkerd, Swelling, erosion and release behavior of alginate-based matrix tablets, Eur. J. Pharm. Biopharm. 66 (2007) 435-450.

[245] Y. Baimark, Y. Srisuwan, Preparation of alginate microspheres by water-in-oil emulsion method for drug delivery: effect of $\mathrm{Ca} 2+$ post-cross-linking, Adv. Powder Technol. 25 (2014) 1541-1546.

[246] P. Sriamornsak, J. Nunthanid, M. Luangtana-anan, Y. Weerapol, S. Puttipipatkhachorn, Alginate-based pellets prepared by extrusion/ spheronization: effect of the amount and type of sodium alginate and calcium salts, Eur. J. Pharm. Biopharm. 69 (2008) 274-284.

[247] M. Xie, Y. Xu, J. Liu, T. Zhang, H. Zhang, Preparation and characterization of folate targeting magnetic nanomedicine loaded with cisplatin, J. Nanomater. 2012 (2012) 1-9.

[248] A.L. Urzedo, M.C. Goncalves, M.H.M. Nascimento, C.B. Lombello, G. Nakazato, A. B. Seabra, Cytotoxicity and antibacterial activity of alginate hydrogel containing nitric oxide donor and silver nanoparticles for topical applications, ACS Biomater. Sci. Eng. 6 (2020) 2117-2134.

[249] P. Chomto, J. Nunthanid, Physicochemical and powder characteristics of various citrus pectins and their application for oral pharmaceutical tablets, Carbohyd. Polym. 174 (2017) 25-31.

[250] T.W. Wong, G. Colombo, F. Sonvico, Pectin matrix as oral drug delivery vehicle for colon cancer treatment, AAPS PharmSciTech 12 (2011) 201-214.

[251] J.-H. Lee, Y.-K. Lee, Y.-R. Choi, J. Park, S.K. Jung, Y.H. Chang, The characterization, selenylation and anti-inflammatory activity of pectic polysaccharides extracted from Ulmus pumila L, Int. J. Biol. Macromol. 111 (2018) 311-318.

[252] R.C. Mundargi, S.A. Patil, S.A. Agnihotri, T.M. Aminabhavi, Development of polysaccharide-based colon targeted drug delivery systems for the treatment of amoebiasis, Drug Dev. Indus. Pharm. 33 (2007) 255-264.

[253] A.M.G. Eldeen, H. Amer, W.A. Helmy, Cancer chemopreventive and antiinflammatory activities of chemically modified guar gum, Chem. Biol. Interact. 161 (2006) 229-240.

[254] P.F. Builders, M.I. Arhewoh, Pharmaceutical applications of native starch in conventional drug delivery, Starch 68 (2016) 864-873.

[255] P. Prasher, M. Sharma, S.P. Singh, Drug encapsulating polysaccharide-loaded metal nanoparticles: a perspective drug delivery system, Drug Dev. Res. 82 (2021) $145-148$.

[256] R.M. Daudt, I.C.K. Guerreiro, F.C. Olivera, R.C.S. Thys, L.D.F. Marczak, Determination of properties of pinhão starch: analysis of its applicability as pharmaceutical excipient, Ind. Crop Product 52 (2014) 420-429.

[257] A.P. Almeida, S.R. Rojo, A.T. Serra, H.-V. Real, A.-L. Simplicio, I. Delgadilho, S, V. Costa, L.B. Costa, Microencapsulation of oregano essential oil in starch-based materials using supercritical fluid technology, Innovat. Food Sci. Innovative Technol. 20 (2013) 140-145.

[258] K. Luo, H.J. Adra, Y.-R. Kim, Preparation of starch-based drug delivery system through the self-assembly of short chain glucans and control of its release property, Carbohyd. Polym. 243 (2020), 116385.

[259] E. Alp, F. Dmkaci, E. Guven, M. Tenniswood, Starch nanoparticles for delivery of the histone deacetylase inhibitor CG-1521 in breast cancer treatment, Int. J. Nanomed. 14 (2019) 1335-1346.

[260] Y. Shao, L. Li, X. Gu, L. Wang, S. Mao, Evaluation of chitosan-anionic polymers based tablets for extended-release of highly water-soluble drugs, Asian J. Pharm. Sci. 10 (2015) 24-30.
[261] F. Damiri, Y. Bachra, C. Bounacir, A. Laaraibi, M. Berrada, Synthesis and characterization of lyophilized chitosan-based hydrogels cross-linked with benzaldehyde for controlled drug release, J. Chem. 2020 (2020) 1-10.

[262] R.A. Fitaihi, F.S. Aleanizy, S. Elsamaligy, H.A. Mahmoud, M.A. Bayomi, Role of chitosan on controlling the characteristics and antifungal activity of bioadhesive fluconazole vaginal tablets, Saudi Pharm. J. 26 (2018) 151-161.

[263] R.V. Pai, R.R. Jain, A.S. Bannalikar, M.D. Menon, Development and evaluation of chitosan microparticles based dry powder inhalation formulations of rifampicin and rifabutin, J. Aerosol Med. Pulmon. Drug Deliv. 29 (2016) 179-195.

[264] R.K. Dutta, S. Sahu, Development of diclofenac sodium loaded magnetic nanocarriers of pectin interacted with chitosan for targeted and sustained drug delivery, Colloid. Surf. B 97 (2012) 19-26.

[265] W. Zhou, L. Zou, C. Liu, R. Liang, J. Chen, Storage stability and skin permeation of vitamin C liposomes improved by pectin coating, Colloid. Surf. B 117 (2014) 330-337.

[266] M. Sharma, R. Malik, A. Verma, P. Dwivedi, G.S. Banoth, N. Pandey, J. Sarkar, P. R. Mishra, A.K. Dwivedi, Folic acid conjugated guar gum nanoparticles for targeting methotrexate to colon cancer, J. Biomed. Nanotechnol. 9 (2013) 96-106.

[267] R. Kaur, T. Garg, B. Malik, U.D. Gupta, P. Gupta, G. Rath, A.K. Goyal, Development and characterization of spray-dried porous nanoaggregates for pulmonary delivery of anti-tubercular drugs, Drug Deliv. 23 (2016) 872-877.

[268] X. Yuan, R. Amarnath Praphakar, M.A. Munusamy, A.A. Alarfaj, S. Kumar, M. Rajan, Mucoadhesive guargum hydrogel inter-connected chitosan-gpolycaprolactone micelles for Rifampicin delivery, Carbohyd. Polym. 206 (2019) $1-10$.

[269] D.E. Ciolacu, R. Nicu, F. Ciolacu, Cellulose-based hydrogels as sustained drugdelivery systems, Materials 13 (2020), 5270.

[270] K.S. Mikkonen, Strategies for structuring diverse emulsion systems by using wood lignocellulose-derived stabilizers, Green Chem. 22 (2020) 1019-1037.

[271] C. Costa, B. Medronho, A. Filipe, I. Mira, B. Lindman, H. Edlund, M. Norgren, Emulsion formatino and stabilizatin by biomolecules: the leading role of cellulose, Polymers 11 (2019), 1570.

[272] B. Wang, H. Tian, D. Xiang, Stabilizing the oil-in-water emulsion using the mixtures of Dendrobium Officinale polysaccharides and gum arabic or propylene glycol alginate, Molecules 25 (2020), 759.

[273] S. Lombardo, A. Villares, Engineered multilayer microcapsules based on polysaccharide nanomaterials, Molecules 25 (2020), 4420.

[274] R. Koshani, M. Tavakolian, T.G.M. Ven, Natural emulgel from dialdehyde cellulose for lipophilic drug delivery, ACS Sustain. Chem. Eng. 9 (2021) 4487-4497.

[275] S.D. Riedl, E. Hausmann, H.D. Schick, R. Bender, et al., Phase I clinical and pharmacokinetic trial of dextran conjugated doxorubicin (AD-70, DOX-OXD), Invest. New Drug 11 (1993) 187-195.

[276] O. Soepenberg, M.J.A. Jonge, A. Sparreboom, P. Bruin, F.A.L.M. Eskens, G. Heus, J. Wanders, P. Cheverton, M.P. Ducharme, J. Verweji, Phase I and pharmacokinetic study of DE-310 in patients with advanced solid tumors, Clin. Cancer Res. 11 (2005) 703-711.

[277] J.K. Kim, K.-H. Han, J.-T. Lee, Y.-H. Paik, S.H. Ahn, J.D. Lee, K.S. Lee, C.Y. Chon, Y.M. Moon, Long-term clinical outcome of phase IIb clinical trial of percutaneous injection with holmium-166/chitosan complex (Milican) for the treatment of small hepatocellular carcinoma, Clin. Cancer Res. 12 (2006) 543-548.

[278] C. Pinnix, G.H. Perkins, E.A. Strom, W. Tereffe, W. Woodward, J.L. Oh, L. Arriaga, M.F. Munsll, P. Kelly, K.E. Hoffmann, B.D. Smith, T.A. Buchholz, T.K. Yu, Topical hyaluronic acid vs. standard of care for the prevention of radiation dermatitis after adjuvant radiotherapy for breast cancer: single-blind randomized phase III clinical trial, Int. J. Radiat. Oncol. Biol. Phys. 83 (2012) 1089-1094.

[279] M.F. Pritchard, L.C. Powell, G.E. Menzies, P.D. Lewis, K. Hawkins, C. Wright, I. Doull, T.R. Walsh, E. Onsoyen, E. Dessen, R. Myrvold, P.D. Rye, A.H. Myrset, H. N.E. Stevens, L.A. Hodges, G.M. Gregor, J.B. Neilly, K.E. Hill, D.W. Thomas, A New class of safe oligosaccharide polymer therapy to modify the mucus barrier of chronic respiratory disease, Mol. Pharm. 13 (2016) 863-872. 